\title{
Del mar a la tumba. Hallazgos de utensilios de pesca en las necrópolis de Gadir/Gades
}

\section{From the sea to the grave. Fishing tools findings in the necropolis of Gadir/Gades}

\author{
JosÉ MANUEL VARGAS GIRÓN \\ Departamento de Ciencias Históricas. Área de Arqueología \\ Facultad de Filosofía y Letras \\ Universidad de Málaga \\ Campus de Teatinos s/n., 29071 Málaga \\ josemvargas@uma.es \\ https://orcid.org/0000-0003-2882-8902
}

\begin{abstract}
Resumen
El estudio de los instrumentos de pesca atendiendo al contexto arqueológico donde quedaron sepultados es una línea de investigación de gran interés para reconstruir los diferentes usos y funciones que tuvieron este tipo de artefactos durante la Antigüedad. En este trabajo se presentan una serie de evidencias de instrumental pesquero procedentes de diferentes contextos funerarios excavados en las necrópolis de Gadir/Gades, estableciéndose una categorización de los ambientes donde fueron hallados (niveles deposicionales, estructuras relacionadas con el funcionamiento interno de las necrópolis y tumbas). Se tratará de explicar el papel que jugaron las artes de pesca en las necrópolis gaditanas en clave diacrónica, valorándose la importancia de la figura del pescador en las ceremonias funerarias. Por otro lado, la presencia de material pesquero formando parte de los ajuares de los difuntos permitirá aproximarnos a los ritos y tipos de tumbas utilizados en los enterramientos de los pescadores.
\end{abstract}

Palabras clave: instrumental pesquero, ajuar, tumbas, necrópolis, Gadir/Gades

\section{Abstract}

The study of the fishing tools, taking into account the archaeological context where they were buried, is a very interesting line of research in order to reconstruct the different uses and functions that these kinds of utensils had during the ancient times. In this work, a series of evidences of fishing devices coming from different funerary contexts excavated in the necropolis of Gadir/Gades are submitted. A catalogue of the environment where they were found (depositional levels, frameworks related to the internal functioning of the necropolis and the graves) is established. An attempt to explain the role played by the fishing gears in the necropolis of Cadiz will be done in a diachronic way, putting into value the importance of the figure of the fisherman in the funeral ceremonies. On the other hand, the presence of fishing material in the grave goods will allow an approach to the rites and types of graves used in the fishermen burials.

Key words: fishing instrumental/tools, grave goods, graves, necropolis, Gadir/Gades 


\section{Introducción}

Desde los primeros momentos de la existencia humana, la pesca ha constituido una de las principales actividades en el marco de la economía de subsistencia de las poblaciones costeras del Mediterráneo (Purcell, 1995). Con las primeras colonizaciones fenicias hacia Occidente, la actividad pesquera adquirirá, además, un carácter industrial sin precedentes gracias a la transformación, elaboración y comercialización de toda una amplia gama de productos derivados de la pesca, básicamente salsas y salazones de pescado (Moya, 2016). En este sentido, resulta lógico pensar que las investigaciones sobre la arqueología de la pesca se hayan centrado tradicionalmente en torno a los grandes centros pesqueros-conserveros donde se fabricaban estos afamados productos - cetariae (http://ramppa.uca.es/)— así como en los envases encargados de su transporte —ánforas (http://amphorae. icac.cat/)—, a lo que tenemos que sumar en los últimos años tres líneas muy novedosas: el estudio de las evidencias de instrumental pesquero, la determinación de las especies marinas consumidas - ictiología y malacología - y la caracterización de los ingredientes que formaban parte de las producciones piscícolas.

Sin embargo, poco o casi nada se sabe acerca de la figura del pescador en la Antigüedad, ya se traten de pescadores dedicados profesionalmente a este oficio o ya sean gentes que se dediquen de una manera más o menos esporádica a nivel de ocio o de subsistencia (Hanson, 1997). A través de las fuentes literarias es posible analizar la visión que los autores antiguos tenían sobre los pescadores ya que en sus textos se describen cuales debían ser sus condiciones ideales, tanto físicas como intelectuales. Desde esta perspectiva, se considera que para la perfecta ejecución de las prácticas de pesca se requería a personas jóvenes en plena forma, con mucha fuerza e inteligentes (Opp. H. III, 29-49). Esta información proporcionada por Opiano puede contrastarse con las representaciones de pescadores documentadas en la iconografía antigua, fundamentalmente en la musivaria romana. Por ejemplo, en algunos paneles musivos del norte de África aparecen modelos de jóvenes pescadores cuya desnudez nos permite apreciar sus rasgos anatómicos. En la mayoría de los casos se representan muchachos con pectorales, abdominales y bíceps muy marcados y en constante movimiento, unas veces agachados, otras de pie, remando y en algún que otro caso en el interior del agua nadando.

Otros autores, principalmente comediógrafos grecolatinos, ofrecen, sin embargo, una visión de los pescadores totalmente diferente. Efectivamente, algunos escritores de comedia utilizan la figura del pescador como personajes de sus obras, convirtiéndolos en el centro de todas las burlas (Plaut. Capt. Acto IV, Escena II; Plaut. Rud. Acto II, Escena I; Acto I, Escena II). Otros géneros, tales como la fábula y la epístola, hacen hincapié en las humildes condiciones de vida de los pescadores (Teócrito, Idilios, XXI, I-67) así como en la peligrosidad de los trabajos del mar (Alcifrón, Cartas, I, 3, I-3; Io, I-5). Aspectos sociales han sido también tratados por los textos clásicos, incidiéndose en las pésimas condiciones laborales de los pescadores $\mathrm{y}$ en el fuerte descontento social de los mismos para con los patrones (Alcifrón, Cartas, I, 2, 2-4).

Otra de las fuentes de información de la que disponemos para el estudio de los pescadores antiguos es la documentación epigráfica (Robert, 1950), conservándose actualmente cuatro inscripciones - una procedente de la isla de Cos y las tres restantes recuperadas en dos poblaciones ribereñas del mar Negro (Cízico y Pario)-, donde se recogen interesantes datos para reconstruir el ciclo de la captura del atún en la Antigüedad, desde el avistamiento de los cardúmenes en las torres vigía (thynnoskopeia) hasta el despliegue de las almadrabas, mencionándose las asociaciones de pescadores que participaban en las artes de redes y el papel que cumplía cada uno de ellos en este entramado profesional (Bekker-Nielsen, 20Io; García Vargas, 2016).

Por lo que respecta a las evidencias materiales, la visibilidad arqueológica de los pescadores en la Antigüedad se encuentra limitada al estudio de sus tumbas. Desde un punto de vista antropológico, resulta verdaderamente complejo determinar si un enterramiento pertenece o no a un pescador, si bien la aplicación de nuevas técnicas forenses sobre restos humanos antiguos podría aportarnos interesantes datos sobre múltiples cuestiones (esperanza de vida, determinación de posibles enfermedades derivadas del oficio de pescador, alimentación, aspecto físico, 
entre otros). Otra de las líneas de trabajo de la que se podría extraer muy buenos resultados es el análisis de los ajuares depositados en el interior de las tumbas. En este sentido, la aparición de determinados elementos de ajuar acompañando al cuerpo del difunto, como pueden ser utensilios y artes de pesca, podría convertirse en un elemento clave a la hora de determinar el oficio de la persona allí enterrada (AA.VV., 1992: 299; Campos et alii, I999; Fernández Sutilo, 2016; Rubio Gomis, 1986).

En un reciente trabajo de investigación (Vargas, 20I7, 2020) se han catalogado un total de 915 evidencias de instrumental pesquero procedentes de diferentes yacimientos arqueológicos descubiertos en Cádiz, Alicante y Murcia, abarcando una cronología del siglo v a. C. al siglo vi d. C. Uno de los objetivos prioritarios de este corpus documental ha sido estudiar los materiales atendiendo a su contexto arqueológico, habiéndose podido comprobar que uno de los ambientes donde suelen aparecer frecuentemente instrumenta piscatoria son las necrópolis.

El objetivo de este artículo es presentar los instrumentos de pesca documentados en las necrópolis de Gadir/Gades, incidiendo en la problemática arqueológica que implica cualquier aproximación a los contextos funerarios gaditanos (Arévalo y Moreno, 20I6). Se tratará de establecer una categorización de los diferentes ambientes donde suelen aparecer este tipo de artilugios, así como determinar cuáles fueron sus usos y funciones y los motivos que explicarían su presencia en las necrópolis.

\section{Instrumenta piscatoria en el mundo funerario gaditano. Un primer escrutinio}

En el marco del Proyecto de Investigación de Excelencia Sagena ${ }^{1}$ se llevó a cabo un estudio del instrumental pesquero almacenado entre los fondos

1 El proyecto Sagena (2008-20II), denominado «Artes de pesca en Andalucía en la Antigüedad. Modelización de la metodología de investigación arqueológica e inicios del corpus documental», ha sido liderado por un grupo de investigación interdisciplinar de la Universidad de Cádiz bajo la dirección científica del profesor Darío Bernal-Casasola. del Museo de Cádiz, habiéndose revisado un total de 44 yacimientos arqueológicos de diferentes localidades de la provincia gaditana (San Roque, Tarifa, Barbate, Cádiz, El Puerto de Santa María, Chipiona y Sanlúcar de Barrameda). En lo que se refiere al caso concreto de la ciudad de Cádiz, se han documentado interesantes evidencias de instrumentos de pesca en un total de 35 intervenciones arqueológicas de urgencia realizadas en la capital gaditana desde principios del siglo xx hasta la actualidad, una cifra que deja entrever la importancia de las actividades pesqueras en Gadir/Gades. De todos los solares que han sido investigados (35), hemos podido determinar que en 20 de ellos se han documentado contextos funerarios con artefactos de pesca asociados, cuyo análisis constituye la piedra angular de este trabajo. A la hora de dar a conocer estos hallazgos, hemos decidido agruparlos atendiendo a las intervenciones donde fueron recuperados (figura I), para cuya ordenación hemos seguido un criterio alfabético.

\subsection{Avenida Amílcar Barca (Tesorería General de la Seguridad Social)}

En las excavaciones realizadas en el solar de la actual Tesorería General de la Seguridad Social (figura I, I) se documentaron un total de 26 enterramientos así como una serie de estructuras que, a juicio de sus excavadores, podrían estar relacionadas con las propias tumbas (Sibón, 200I). Entre estas construcciones destaca la aparición de tres pozos excavados y perfectamente alineados siguiendo un eje norte-sur, en uno de los cuales apareció una aguja de bronce completa con vástago de sección romboidal (figura 2, I). El hallazgo tuvo lugar en el nivel I del pozo $\mathrm{n}^{\mathrm{o}}$ 2, que se localiza dentro de una gran fosa excavada en la arcilla, habiéndose establecido su cota de aparición en -2,39 $\mathrm{m}$ desde el punto 0 . El pozo aparece construido en dos cuerpos, el primero de los cuales está constituido por mampostería a base de piedras irregulares y cantos rodados mientras que el segundo aparece tallado directamente sobre la roca. $\mathrm{La}$ aguja se documenta en el nivel I del pozo, es decir, en el relleno correspondiente al primer cuerpo de la estructura (figura 3). Se trata de un nivel de matriz arenosa y de coloración castaño oscuro, cuya potencia 


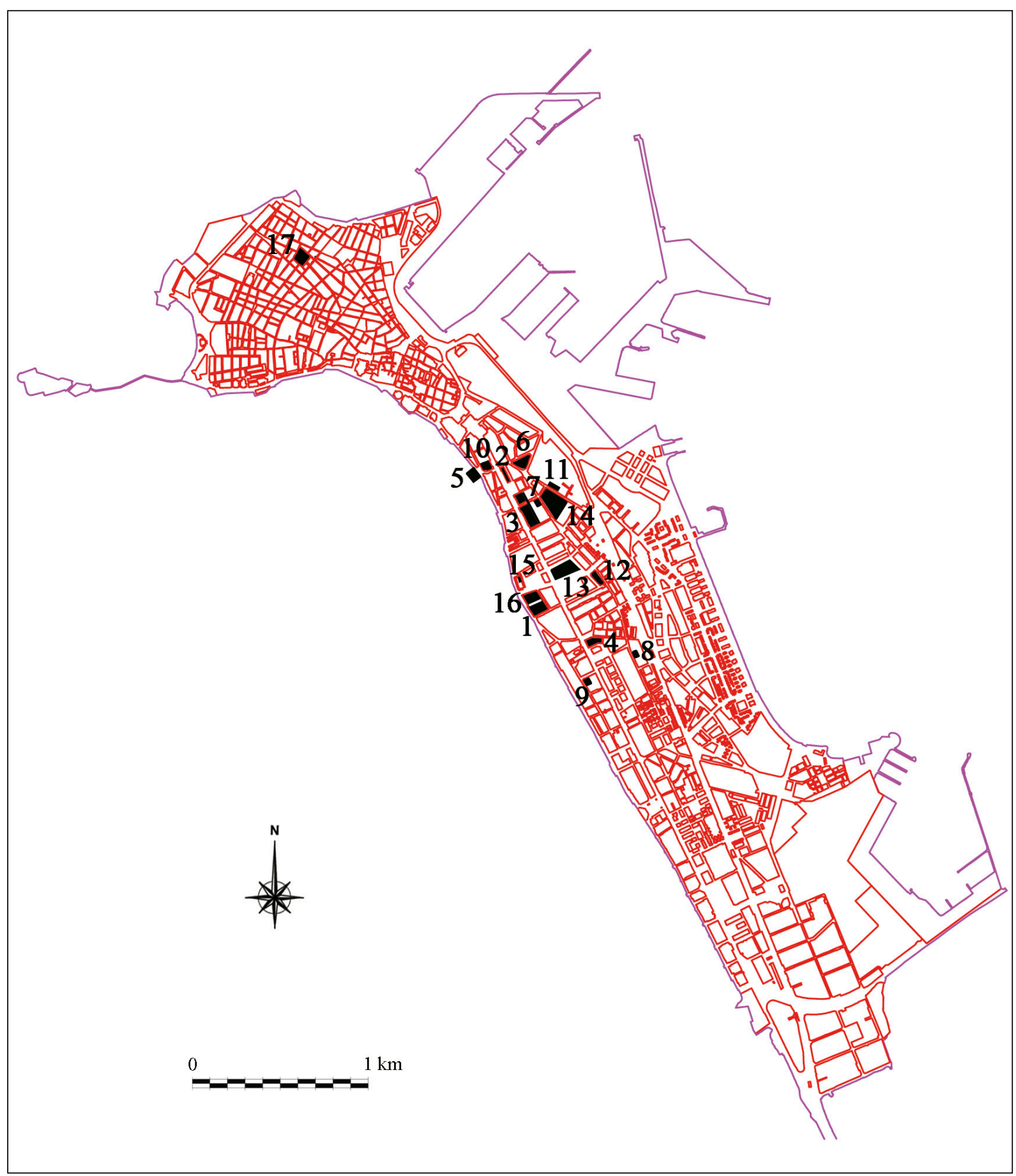

Figura 1. Plano de la ciudad de Cádiz con indicación de los solares donde se han realizado las intervenciones arqueológicas comentadas en el texto. 1. Avenida Amílcar Barca (Tesorería General de la Seguridad Social); 2. Avenida Andalucía 21-27 y calle General Ricardos 2; 3. Avenida López Pinto (1980); 4. Avenida Portugal esquina a avenida Andalucía; 5. Baños del Blanco; 6. Calle Acacias, 21, 23 y 25; 7. Calle Brunete 2; 8. Calle García Carrera 9; 9. Calle San Juan Bautista esquina a calle Marqués de Coprani; 10. Calle Santa Cruz de Tenerife 1 esquina a calle Santa María del Mar; 11. Calle Tolosa Latour (1987); 12. Cuarteles de Varela (calle Marqués de la Ensenada y avenida de la Constitución 1812, fase II, 2000); 13. Cuarteles de Varela (avenida Andalucía, s/n); 14. Palacio de la Justicia; 15. Plaza Asdrúbal (1985); 16. Plaza Asdrúbal (1997-1998); 17. Plaza San Antonio

Figure 1. Plan of the city of Cadiz with site signs where the archaeological interventions discussed in the text have been carried out. 1. Avenida Amílcar Barca (Tesorería General de la Seguridad Social); 2. Avenida. Andalucía 21-27 and calle General Ricardos 2; 3. Avenida López Pinto (1980); 4. Avenida Portugal corner with avenida Andalucía; 5. Baños del Blanco; 6. Calle Acacias, 21, 23 and 25; 7. Calle Brunete 2; 8. Calle García Carrera 9; 9. Calle San Juan Bautista corner with calle Marqués de Coprani; 10. Calle Santa Cruz de Tenerife 1 corner with calle Santa María del Mar; 11. Calle Tolosa Latour (1987); 12. Cuarteles de Varela (calle Marqués de la Ensenada and avenida de la Constitución 1812, $2^{\text {nd }}$ phase, 2000); 13. Cuarteles de Varela (avenida Andalucía); 14. Palacio de la Justicia; 15. Plaza Asdrúbal (1985); 16. Plaza Asdrúbal (1997-1998); 17. Plaza San Antonio 


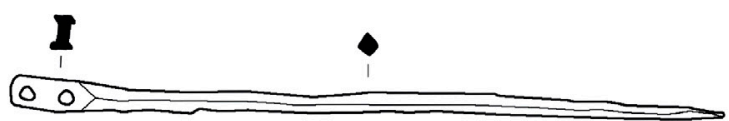

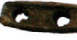

1
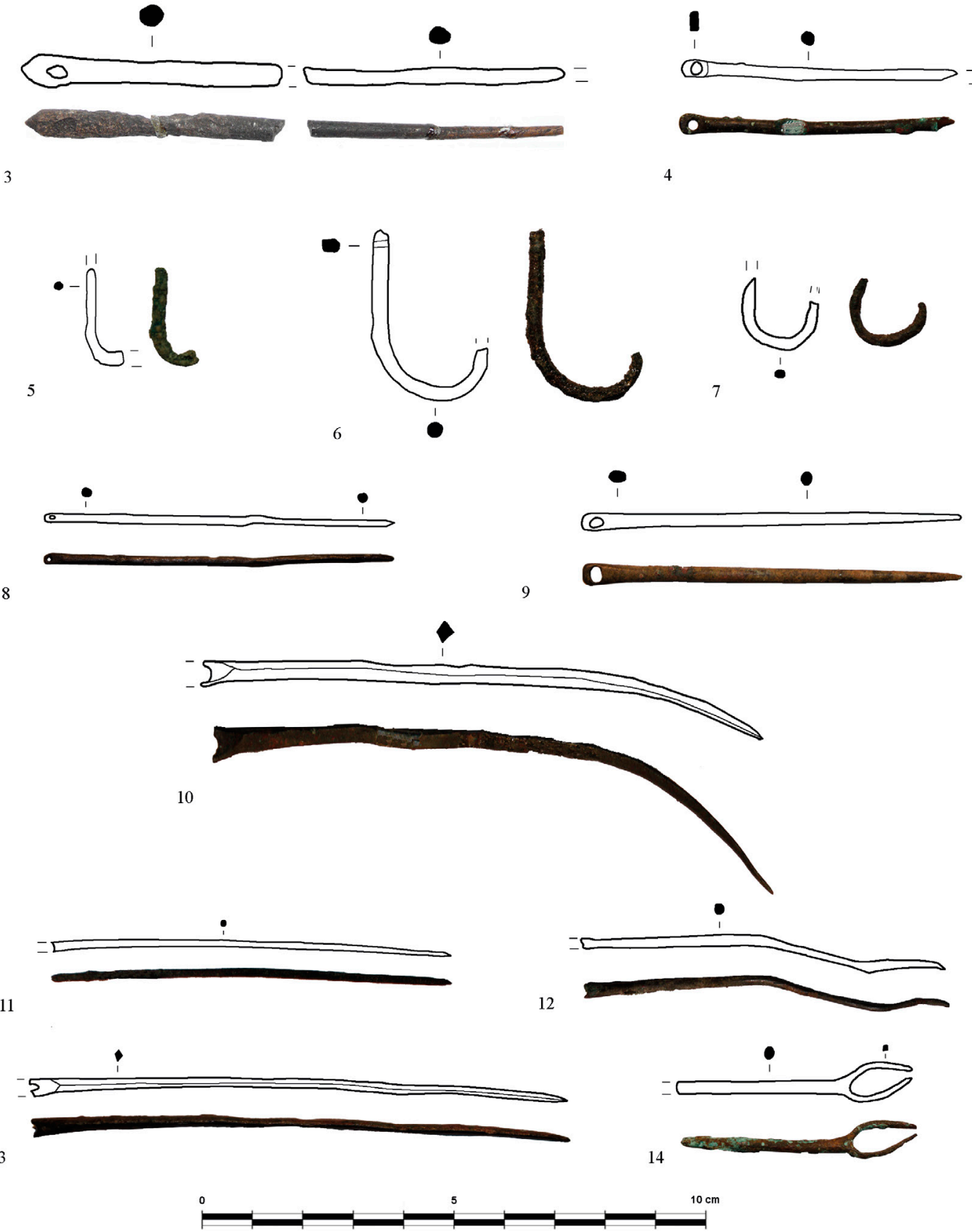

Figura 2. Instrumental pesquero procedente de avenida Amílcar Barca/Tesorería General de la Seguridad Social ( $n^{\circ}$ 1: aguja de bronce), avenida Andalucía 21-27 y calle General Ricardos 2 ( $n^{\circ}$ 2: aguja de bronce; $n^{\circ}$ 3: aguja de hueso), avenida López Pinto ( $n^{\circ}$ 4: aguja de bronce), avenida Portugal esquina a avenida Andalucía ( $n^{\circ}$ 5: anzuelo) y Baños del Blanco ( ${ }^{\circ s} 6$ y $7:$ anzuelos; $\mathrm{n}^{\text {os }}$ 8-13: agujas de bronce; $\mathrm{n}^{\circ}$ 14: lanzadera)

Figure 2. Set of fishing instruments coming from avenida Amílcar Barca/Tesorería General de la Seguridad Social (no. 1: bronze needle), avenida Andalucía 21-27 and calle General Ricardos 2 (no. 2: bronze needle; no. 3: bone needle), avenida López Pinto (no. 4: bronze needle), avenida Portugal corner with avenida Andalucía (no. 5: fishhook) and Baños del Blanco (nos. 6 and 7: fishhooks; nos. 8-13: bronze needle; no. 14: shuttle) 


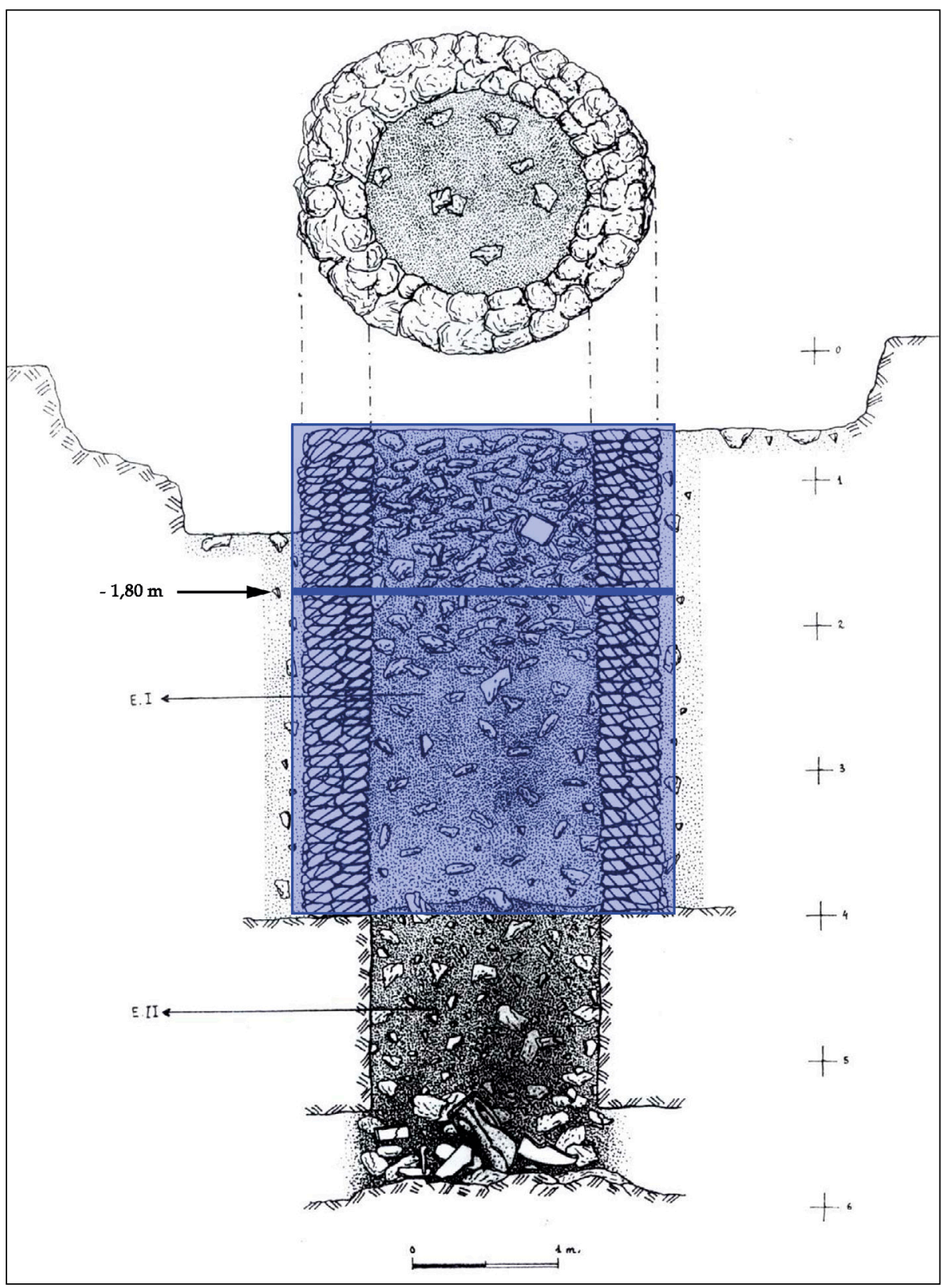

Figura 3. Planta, perfil y sección del pozo $\mathrm{n}^{\circ} 2$ documentado en la avenida Amílcar Barca/Tesorería General de la Seguridad Social (elaboración propia a través del original de Sibón, 2001). En color azul señalamos la situación del nivel 1, resaltando, con una coloración más intensa, la cota de aparición de la aguja de bronce presentada en este trabajo

Figure 3. Plan, shape and cross-section views of the well number 2 documented in avenida Amílcar Barca/Tesorería General de la Seguridad Social (own elaboration following the original one by Sibón, 2001). Outlined in blue colour, the situation of level 1 can be found, and highlighted with a brighter colour, the appearance altitude of the bronze needle exposed in this project

estratigráfica es de 3,35 $\mathrm{m}$ desde la superficie del pozo, presentando una anchura máxima de r,6o m justo en el punto donde termina la mampostería y comienza la parte tallada en la roca (Sibón, 20or: 46).

Por lo que respecta a los materiales arqueológicos aparecidos en este nivel de relleno, la mayoría de los restos son cerámicos, habiéndose recuperado cerámicas comunes romanas, sigillatas africanas del tipo A así como fragmentos de mármoles y lápidas. Tanto el primer nivel de relleno, correspondiente al primer cuerpo del pozo, como el segundo nivel, perteneciente al relleno del pozo tallado en la roca, han podido datarse en época romana altoimperial, y más concretamente entre finales del siglo i y 
la primera mitad del siglo II. Por otra parte, en el exterior del pozo se realizó un sondeo estratigráfico junto al brocal que ha servido para fechar su momento de construcción hacia el siglo in a. C., gracias a la aparición de fragmentos de cerámica campaniense A (Sibón, 200r: 46-49).

\subsection{Avenida Andalucía 21-27 y calle General Ricardos 2}

Los trabajos arqueológicos llevados a cabo en este gran solar situado a extramuros del Centro Histórico de la ciudad de Cádiz (figura I, 2) han deparado resultados espectaculares, habiéndose documentado un total de 203 enterramientos más los restos de cuatro columbarios, todo ello datado entre el siglo ir a. C.y el siglo ir d. C. (Córdoba y Navarro, I999). Entre los restos de cultura material se recuperaron una aguja de bronce fragmentada con vástago de sección cilíndrica (figura 2, 2) así como una aguja de hueso incinerada (figura 2, 3), cada una de las cuales procedentes de contextos arqueológicos diferenciados. En el caso de la primera (figura 2, 2), su hallazgo tuvo lugar en una de las diez tumbas de incineración en urna de cerámica documentadas en este yacimiento, concretamente en la T-137 (Corte D). Por su parte, la aguja ósea (figura 2,3 ) apareció en una de las 33 tumbas de incineración en fosa simple primaria localizadas en esta intervención, y más concretamente en la T-I79. Aunque no tenemos datos fehacientes al respecto, es posible que estas agujas aparecieran formando parte de los ajuares funerarios junto a los restos calcinados de sendos individuos. En el caso del ejemplar óseo, esta hipótesis podría verse corroborada gracias a que la aguja presenta signos de haber estado en contacto con fuego, por lo que pudo haber sido incinerada junto al cuerpo del difunto.

\subsection{Avenida López Pinto 1980}

Otros hallazgos de época romana altoimperial tuvieron lugar en las excavaciones realizadas en la avenida López Pinto de Cádiz (figura I, 3) durante el año I980, de donde procede una aguja de coser de bronce (figura 2, 4). Los trabajos se desarrollaron durante los primeros trimestres de los años I980 y 198r en dos solares correspondientes a promociones de viviendas dentro de lo que habían sido hasta entonces jardines de un colegio y anteriormente huertas extramuros de la población (Corzo, I989: 240). Este sector de la necrópolis gaditana correspondía, en el momento de su excavación, a los solares nos 35 a 5 de la antigua avenida López Pinto de Cádiz, actualmente conocida como avenida Andalucía. Los trabajos arqueológicos desarrollados permitieron la exhumación de 70 tumbas, 44 de las cuales eran de inhumación -entre las que había 22 tumbas infantiles-y todas ellas eran individuales, a excepción de un mausoleo familiar compuesto por cuatro enterramientos de inhumación. Además, apareció una fila de nichos para urnas cinerarias de fines del siglo i o comienzos del siglo in d. C. (Vaquerizo, 2010: 350).

Durante la campaña de 1980 se excavó el grupo de tumbas infantiles de inhumación que, para algunos autores, podría tratarse de una «inmolación ritual de pequeñas víctimas a las que se había golpeado el cráneo con un objeto contundente» (Corzo, 1992: 278). En este mismo año apareció una aguja de bronce con un único ojal de $0,1 \mathrm{~cm}$ de diámetro (figura 2, 4). Gracias a las referencias encontradas en la ficha de inventario de la pieza (Museo de Cádiz, II276), hemos podido llegar a determinar que su hallazgo tuvo lugar en la tumba no ${ }_{25}(\mathrm{LP} / 25)$. Revisando la documentación publicada por Ramón Corzo, hemos encontrado algunas notas que permiten relacionar esta tumba con uno de los enterramientos infantiles documentados en la avenida López Pinto. En efecto, la tumba L.P/8o/25 pertenece a un niño de cinco años con el cráneo fracturado (Corzo, I989: 242). Además, lo verdaderamente interesante de esta estructura funeraria es que pertenece a un grupo de tumbas (seis en total) que aparecieron perfectamente cerradas y sin alteraciones posteriores. En relación a la cronología de estos enterramientos, Corzo (1992: 24I), quien sostiene que todas las tumbas pertenecen al mismo período de uso, confirma que son de época romana, posiblemente de mediados del siglo i d. C., a tenor de los escasos elementos de ajuar documentados en algunas de las tumbas. Si tenemos en cuenta que la tumba no 25 apareció perfectamente sellada y sin ningún 
tipo de alteración, debemos suponer que esta aguja pudo haber formado parte de su ajuar funerario, aunque los escasos datos con los que actualmente contamos nos obligan a ser cautelosos.

\subsection{Avenida Portugal esquina a avenida Andalucía}

Durante el año 2005 se realizaron intervenciones arqueológicas en el solar ubicado en la avenida Portugal esquina a la avenida Andalucía de Cádiz (figura I, 4) con motivo de la construcción de un hotel. Los trabajos arqueológicos se desarrollaron en cuatro fases, siendo las dos últimas las que permitieron documentar un sector de la necrópolis romana (siglos II-IV d. C.) conformada por 22 enterramientos - 20 de los cuales eran de inhumación y los otros dos restantes de incineración - así como por otras estructuras de posible uso funerario (Blanco y Bueno, 2005).

Por lo que respecta a la aparición de evidencias de instrumental pesquero, sabemos que en el enterramiento no 18 (Cuadro $\mathrm{C}_{-3}$, UE $4 \mathrm{I}$ ) apareció un anzuelo de bronce (figura 2,5 ) en deficiente estado de conservación. Se trata de una posible inhumación en cista de sillares regulares de piedra ostionera depositada en la arena. En lo que se refiere a los restos óseos, se documentaron algunos huesos en muy mal estado de conservación hallados entre varios sillares movidos, a lo que tenemos que sumar la aparición de un cuello de ungüentario de cerámica de tipo helenístico piriforme, varias asas de ánforas púnicas, un fragmento de borde de olla de cerámica común romana con el labio vuelto y el anzuelo que traemos a colación (Blanco y Bueno, 2005: fig. II6).

\subsection{Baños del Blanco}

Sabemos que durante los años I916-I9I7 Pelayo Quintero excava en la zona de Baños del Blanco - figura I, 5- (playa de los Corrales/playa de Santa María del Mar), documentando, entre otras estructuras, una serie de construcciones funerarias. Entre los fondos del Museo de Cádiz se encuentran algunos instrumentos de pesca procedentes de estas excavaciones, habiéndose podido estudiar un total de nueve piezas correspondientes a dos anzuelos (figura 2, 6 y 7), seis agujas de bronce (figura 2, 8-I3) y una lanzadera (figura 2, I4). En relación al contexto arqueológico de los materiales inventariados, no hace falta recordar que, al tratarse de excavaciones tan antiguas, resulta casi imposible precisar sobre esta cuestión. Aun así tenemos noticias acerca de las excavaciones llevadas a cabo por Pelayo Quintero en esta zona extramuros de la ciudad gaditana. En el año I9I7 se retomaron los trabajos iniciados un año antes (I916) en Baños del Blanco, $300 \mathrm{~m}$ al sur. Estas actividades permitieron documentar un sillar pétreo cuyo descubrimiento deparó una construcción ciclópea de piedra ostionera correspondiente a una sepultura en cuyo interior aparecieron restos pertenecientes a tres individuos diferentes, perteneciendo cada uno de ellos a un momento cronológico preciso, según se deduce de la desordenada distribución de las sepulturas. En las inmediaciones de la estructura, apareció un pozo de agua cegado en época romana, relacionándose con los «vecinos» corrales de pesca. En el nivel de relleno del pozo se hallaron una serie de objetos entre los que destacamos un anzuelo (según Pelayo Quintero de cobre), clavos del mismo metal y una moneda romana de cobre de época de Tiberio que ha permitido datar la amortización de esta unidad negativa en época romana altoimperial. Un poco más al norte, en dirección a la ciudad, aparecieron restos de carácter íbero-romano así como de tradición fenicio-púnica (Quintero, 1918: 3-5)

Conocemos, además, un listado con una serie de materiales arqueológicos aparecidos en esta excavación (Quintero, I9I8: 7-8). Estas piezas pertenecen a diferentes horizontes culturales (materiales púnicos, griegos y romanos) y a muy diversa naturaleza (cerámica, vidrio, metal y monedas). En relación al instrumental pesquero, se menciona la aparición de un anzuelo de bronce de $7 \mathrm{~cm}$ de longitud ${ }^{2}$, una pesa de plomo en forma de disco de $200 \mathrm{~g}$ y una aguja de bronce. Todo este panorama que acabamos de

2 Quintero menciona la aparición de un anzuelo de $7 \mathrm{~cm}$ de largo hasta el arranque de la curva (Quintero, I9I8: 8). Sin embargo, a través de la lámina donde se publica este anzuelo (VII) hemos podido comprobar que no se corresponde con ninguno de los dos ejemplares inventariados en este trabajo. 
exponer no nos permite determinar, en absoluto, ni la procedencia exacta ni la cronología de cada uno de los artefactos inventariados en este trabajo.

Por lo que respecta al instrumental pesquero que aquí se presenta, sabemos gracias a las fichas correspondientes a sus números de inventario que los materiales fueron recuperados durante las antiguas excavaciones de Pelayo Quintero en la zona de Baños del Blanco entre los años ı9ı6-ı9ı7, indicándose expresamente el carácter funerario de los ambientes en los que se produjeron los hallazgos («necrópolis íbero-romana»).

\subsection{Calle Acacias 21}

Durante el año I998 se excavaron varios solares contiguos en la calle Acacias de Cádiz (figura I, 6), que comprendían los nos 2I, 23 y 25. Los trabajos arqueológicos realizados en el número $2 \mathrm{I}^{3}$ han permitido documentar un conjunto bastante interesante de instrumental pesquero conformado por cinco anzuelos (figura 4, I-5) y siete agujas (figura 4, 6-I2).

En relación al contexto arqueológico donde se produjeron los hallazgos asistimos a varias situaciones. En primer lugar, contamos con una serie de piezas que podrían haber sido recuperadas del interior de estructuras funerarias, sin haber podido determinar la naturaleza de estos enterramientos. Es el caso del anzuelo $n^{\circ}$ I de la figura 4, procedente de la estructura $3 \mathrm{I}$ (B-280), así como de las agujas $\mathrm{n}^{\text {os }} 9$ y Io (estructura 29, UE 323) y II (estructura III, B-923) de la figura 4. En relación a la $\mathrm{UE}_{323}$ (E-29), de donde proceden las agujas $n^{\text {os }} 9$ y Io, los únicos datos que tenemos sobre este contexto están relacionados con los materiales arqueológicos localizados: dos bordes de ánforas, i6 bordes de cerámica común, dos

3 Sobre esta intervención arqueológica no existe informe/memoria de excavación en la Delegación de Cultura de Cádiz. El único documento administrativo que hemos consultado corresponde a un acta de depósito de materiales (Blanes, I999) que nos ha servido para conocer el contexto cerámico documentado en algunas de las unidades estratigráficas en las cuales han aparecido instrumentos de pesca. Además contamos con los datos proporcionados por Esperanza Mata, quien participó en los trabajos de excavación de este solar, a quien agradecemos sinceramente sus informaciones. asas, ocho fondos y un borde de terra sigillata, tégulas, fragmentos de vidrio y pasta vítrea. El mismo problema tenemos con la aguja no Ir. Gracias a las referencias encontradas en su ficha de inventario (Museo de Cádiz: no 26020), sabemos que procede de la estructura ini, de la cual desconocemos su interpretación si bien hemos podido llegar a determinar los materiales arqueológicos asociados, que corresponden a restos de vidrio.

De otros materiales, sin embargo, hemos podido precisar mejor el contexto arqueológico de su hallazgo. Es el caso de la aguja no 6 de la figura 4, que procede de la UE 404 (B-278) que se corresponde con el primer nivel deposicional de la necrópolis en la cuadrícula 4, tratándose de un estrato de matriz arenosa y coloración marrón oscuro.

Por otro lado, contamos con una serie de piezas cuyo contexto arqueológico no ha podido ser precisado con total claridad. Es el caso de los anzuelos $n^{\text {os }} 2$ y 3 y de las agujas nos 7,8 y I2 de la figura 4, materiales que han sido inventariados de manera conjunta en el Museo de Cádiz ( $n^{\circ}$ 2602I), habiéndose unificado en una misma ficha de inventario los datos de su contexto arqueológico, de ahí que nos resulte imposible determinar a qué unidad estratigráfica pertenece cada objeto. En este sentido, cada una de estas piezas debieron proceder de una de las siguientes UUEE: 404, 204 y 3ro. Sabemos que las UUEE 204 y 404 se corresponden con el primer nivel deposicional de la necrópolis en las cuadrículas 2 y 4 respectivamente. Por lo que respecta a la UE 3 Io, nada sabemos al respecto.

El mismo problema hemos encontrado a la hora de contextualizar el hallazgo de los anzuelos $n^{\text {os }} 4$ y 5 de la figura 4. Los únicos datos que hemos podido obtener nos inducen a pensar que estas piezas fueron halladas en las UUEE 304 y $5 \mathrm{IO}$, sin haber podido determinar a cuál de estas dos unidades estratigráficas pertenecen cada uno de estos anzuelos. Por lo que respecta a la $\mathrm{UE}_{304}$, se trata del primer nivel deposicional relacionado con la necrópolis en la cuadrícula 3. Presenta una composición arenosa y una coloración marrón oscuro. En lo que se refiere a la UE 5 Io, corresponde a una unidad deposicional que rellena una zanja de $5 \mathrm{~m}$ de longitud, I,30 $\mathrm{m}$ de anchura y $0,50 \mathrm{~m}$ de profundidad, localizada al norte de la cista de la incineración E-IoI. 

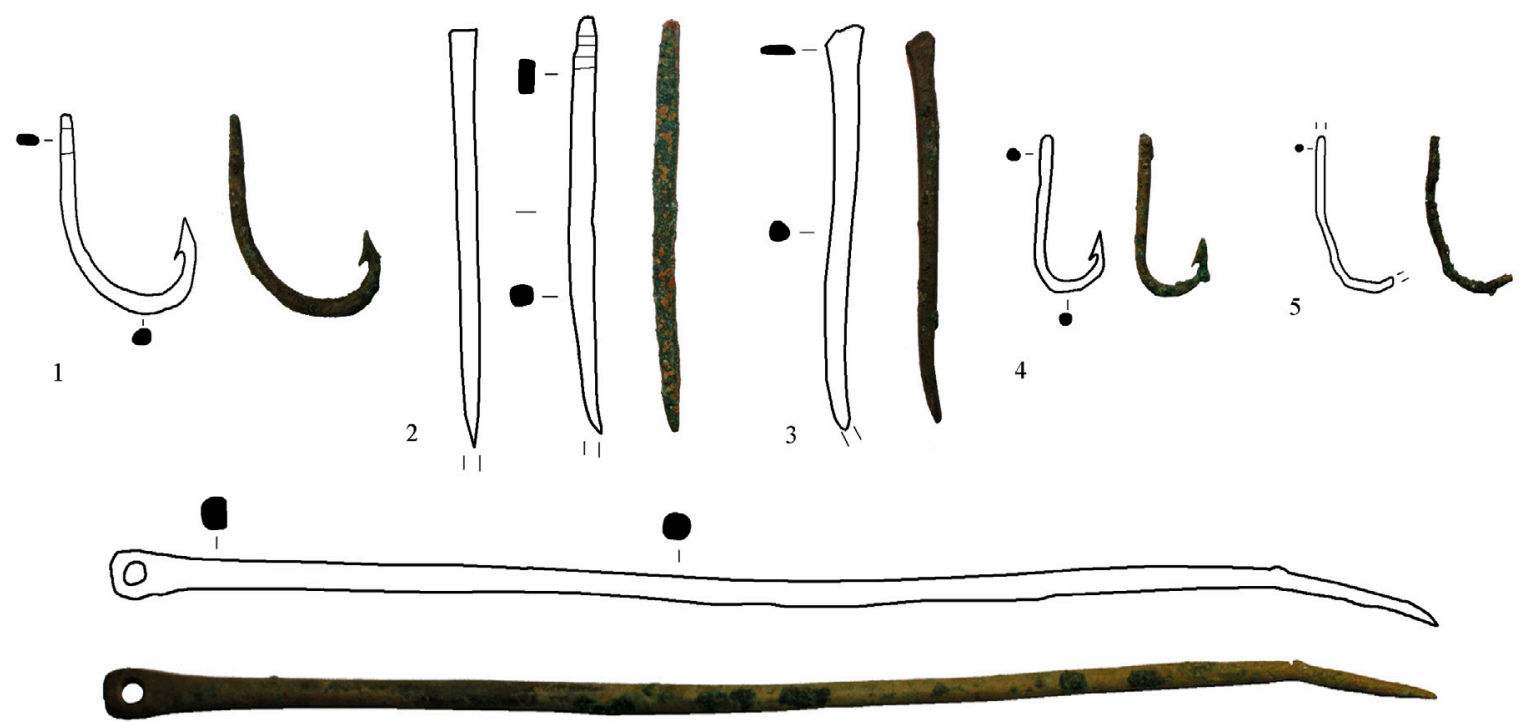

6
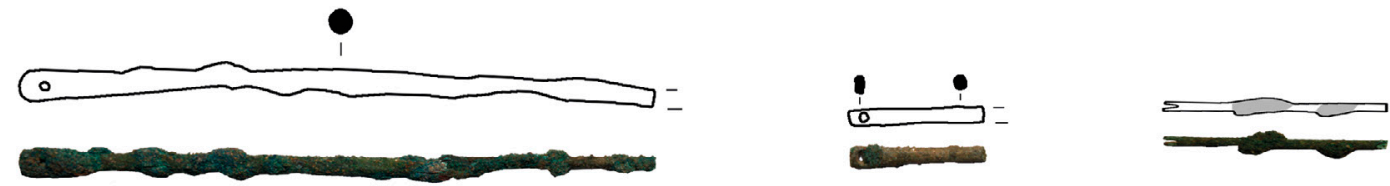

7

8

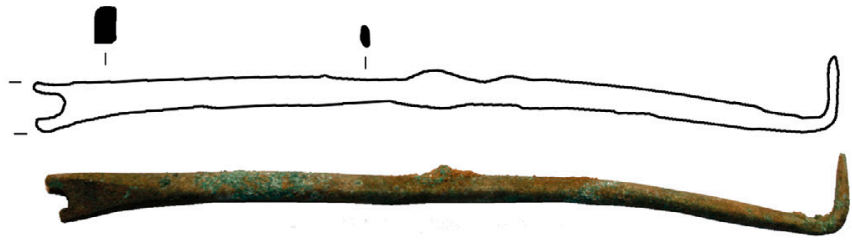

10

11

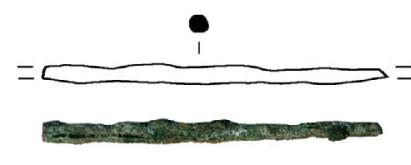

12

13
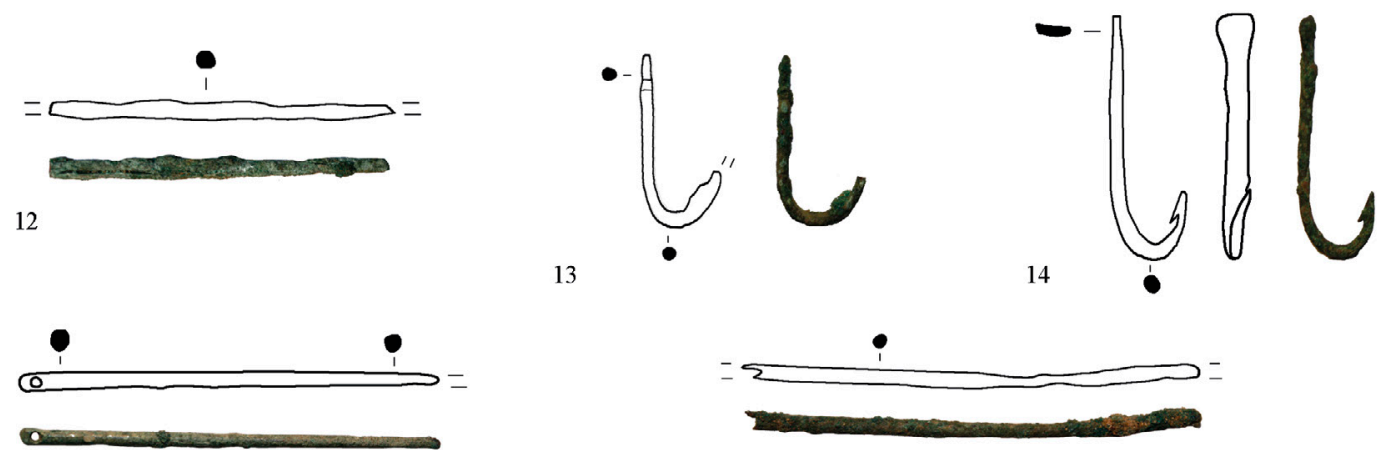

15

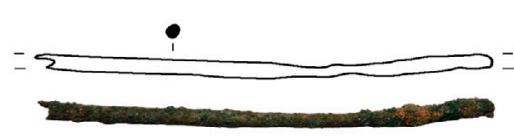

16

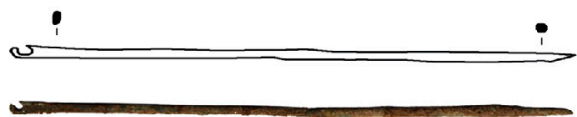

17

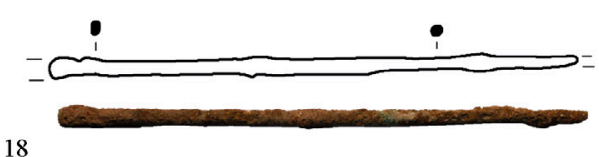

18

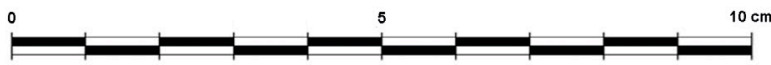

Figura 4. Instrumentos de pesca procedentes de calle Acacias 21 ( $n^{\circ s} 1-5$ : anzuelos; $n^{\circ s}$ 6-12: agujas de bronce), calle Acacias 23 ( $n^{\circ s} 13$ y 14: anzuelos; $n^{\circ}$ 15: aguja de bronce), calle Acacias 25 ( $n^{\circ} 16:$ aguja de bronce) y calle Brunete 2 ( $n^{\circ s} 17$ y 18: agujas de bronce)

Figure 4. Fishing gears coming from calle Acacias 21 (nos. 1-5: fishhooks; nos. 6-12: bronze needles), calle Acacias 23 (nos. 13 and 14: fishhooks; no. 15: bronze needle), calle Acacias 25 (no. 16: bronze needle) and calle Brunete 2 (nos. 17 and 18: bronze needles) 


\subsection{Calle Acacias 23}

Durante el año I998 también se realizaron excavaciones en un solar contiguo al anterior (figura I, 6), concretamente en el número 23 de la calle Acacias. Los trabajos arqueológicos permitieron documentar un sector de la necrópolis gaditana de época romana altoimperial, localizándose un total de 57 enterramientos. Desde un punto de vista metodológico, se abrieron dos cortes en toda la superficie del solar, procediéndose a la excavación del terreno a través de zanjas (diez en total), cada una de las cuales presentaban $2 \mathrm{~m}$ de ancho y una longitud variable atendiendo a las características de la parcela.

La secuencia estratigráfica documentada en cada uno de los cortes era muy uniforme (figura $5, \mathrm{~A}$ ). De este modo, la parte alta de la estratigrafía quedó definida por una serie de paquetes estratigráficos de origen moderno-contemporáneo, llegando a alcanzar una potencia aproximada de $1,40 \mathrm{~m}$. Tras la retirada de estos niveles, que fueron excavados por medios mecánicos, apareció el primer nivel sedimentario de origen antiguo, correspondiendo a un estrato de $0,75 \mathrm{~cm}$ de potencia donde empiezan a aparecer los primeros materiales romanos (UE I). Bajo esta unidad estratigráfica se documentó un nivel de duna (UE 6) de o,50 $\mathrm{m}$ de potencia, habiéndose podido comprobar que en los últimos $20 \mathrm{~cm} \mathrm{la}$ arena adquiere una coloración diferente (tono rosáceo), a lo que tenemos que sumar la aparición tanto de industria lítica como de cerámica a mano de origen prehistórico (figura 5, B y C), motivo por el cual se decidió individualizar como una unidad independiente (UE ir A). Este último estrato apoya directamente sobre la arcilla cuaternaria amarillenta o UE ir (Sibón y Córdoba, I998: IO-II).

El número total de instrumentos de pesca inventariados en este solar es de tres, correspondientes a dos anzuelos simples de bronce (figura 4, I3 y I4) y una aguja del mismo material (figura 4, 15 ). Por lo que respecta a los anzuelos, proceden de un mismo contexto arqueológico, y más concretamente de la tumba 2. Se trata de una incineración en fosa simple cuya cota superior de aparición se ha establecido en $-2,94 \mathrm{~m}$ desde la cota 0 , mientras que la cota de desaparición se encuentra a $-3,27 \mathrm{~m}$ desde la cota 0 .
La tumba se localiza en las zanjas i y 2, habiéndose practicado una fosa que ha sido excavada directamente en la UE 6, siendo cubierta por la UE I. Los materiales arqueológicos documentados en esta tumba están representados por restos óseos quemados, numerosos fragmentos de hierro, un ungüentario de vidrio piriforme, dos monedas de bronce (una de ellas posiblemente de Claudio), y un cuenco-lucerna de cerámica común fragmentado (Sibón y Córdoba, I998: 13). Junto a estos restos se localizaron dos anzuelos de bronce que son los que traemos a colación en este trabajo, aunque en el informe de esta intervención se menciona tan solo la aparición de un ejemplar.

Tenemos noticias de la aparición de un anzuelo de bronce en la tumba 7 de este solar (Sibón y Córdoba, 1998: 16). Este enterramiento, situado en las zanjas I y 2, constituye una inhumación en fosa simple cortada por una incineración (tumba 2) - figura $5, \mathrm{D}$ - . Su cota de aparición se ha establecido entre $-3,40 \mathrm{~m}$ (caderas) y $-3,55 \mathrm{~m}$ (pies) desde la cota 0 , practicándose la fosa directamente sobre la arcilla cuaternaria (UE II), quedando amortizada por la UE 6. El cuerpo apareció en posición decúbito supino con las manos apoyadas sobre la pelvis, la pierna derecha ligeramente flexionada y orientado hacia el este. Alrededor del cuerpo aparecieron numerosos clavos de hierro alineados (22 en total) que indican la presencia de una caja de madera o parihuelas. En la cadera se documentó un ungüentario fusiforme que ha sido datado en época julio-claudia. Además se hallaron dos cuencos de cerámica común, uno de los cuales apareció junto a la rodilla derecha mientras que el otro se documentó a la altura de los pies. La parte superior del cuerpo del difunto apareció totalmente destrozada por la incineración superpuesta, reconociéndose entre los restos del cráneo un nuevo ungüentario fusiforme. Lo verdaderamente interesante de esta tumba para el tema objeto de nuestro estudio ha sido la localización, a la altura de la cadera, de la valva de un molusco bivalvo de especie indeterminada bajo la cual se halló un anzuelo de bronce bien conservado, habiéndose planteado que fue depositado intencionalmente como ajuar funerario (figura 5 , D). Otro hallazgo de especial interés localizado en el interior de la tumba ha sido la aparición de un 

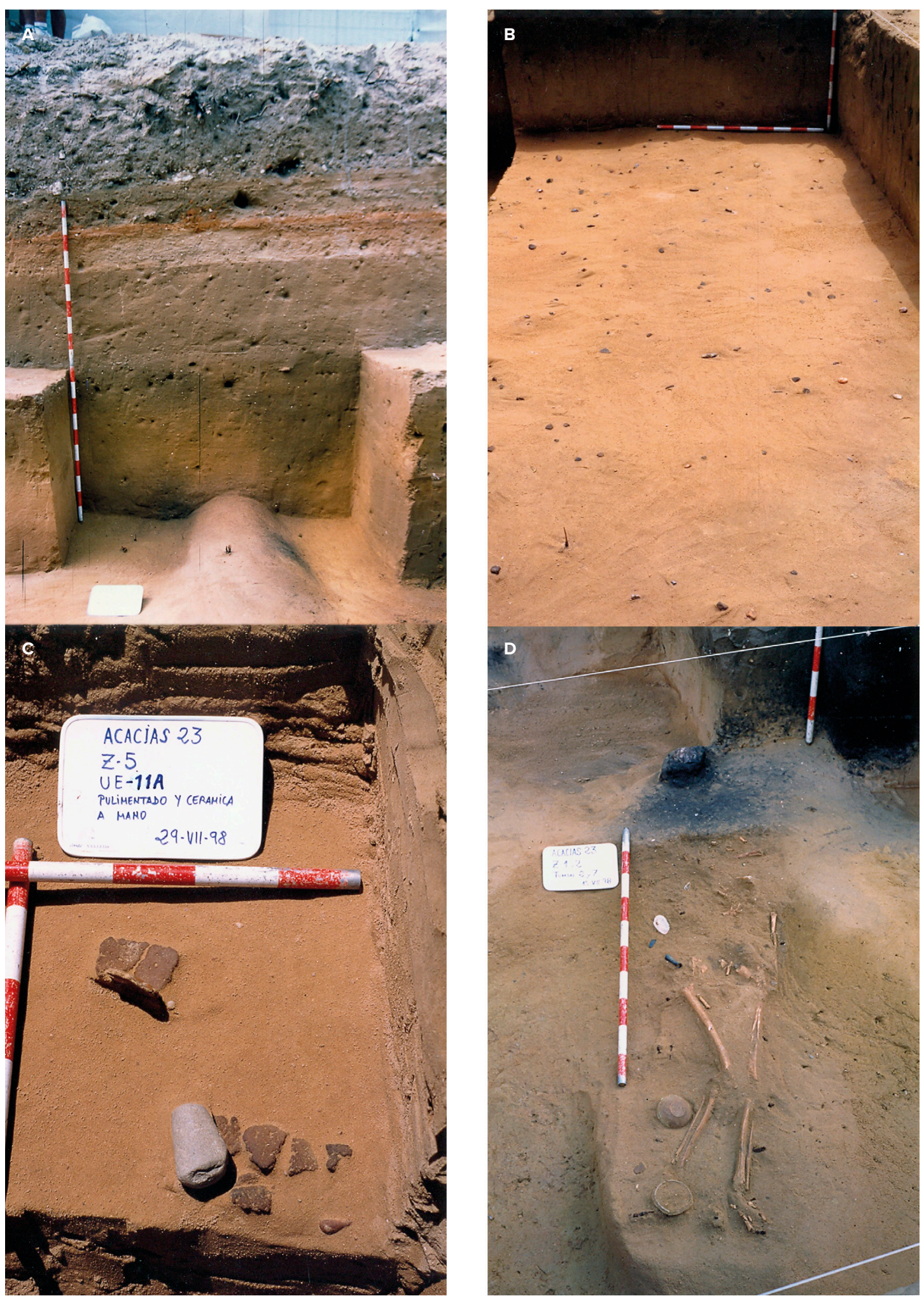

Figura 5. Necrópolis documentada en calle Acacias 23 (elaboración propia a través del original de Sibón y Córdoba, 1998). A. Perfil estratigráfico; B. Vista en planta de la UE 11A con la dispersión de material prehistórico en superficie; C. Detalle de materiales arqueológicos in situ aparecidos en la UE 11A; D. inhumación de la tumba 7 destruida en su cabecera por la incineración de la tumba 2

Figure 5. Necropolis documented in calle Acacias 23 (own elaboration following the original one by Sibón and Córdoba, 1998). A. Stratigraphic profile; B. plan view of UE 11A with the dispersion of prehistorical material on surface; C. detail of archaeological instruments in the UE 11A; D. burial of tomb 7, the top place is missing due to the cremation of tomb 2 
otolito de corvina ${ }^{4}$ a la altura del pecho, que junto al anzuelo sugiere una interesante aproximación al modo de vida del individuo inhumado.

En relación a la única aguja de bronce inventariada (figura 4, 15), a diferencia de los anzuelos, su hallazgo no parece haberse producido en el interior de ninguna estructura funeraria. Procede de la UE 6 (zanja 3) que constituye un nivel sedimentario de arena dunar y de formación eólica, donde se han recuperado materiales republicanos así como elementos de cultura material de tradición fenicio-púnica (Sibón y Córdoba, I998: II). Sobre este nivel se han excavado las fosas de la gran mayoría de los enterramientos documentados en este solar (Sibón y Córdoba, 1998: I2).

\subsection{Calle Acacias 25}

Muy cerca del solar anterior, y más concretamente en el número 25 (figura I, 6), se llevaron a cabo también excavaciones arqueológicas de urgencia durante el año 2005. Los trabajos de campo permitieron documentar una secuencia estratigráfica que abarca un periodo cronológico bastante amplio, desde los niveles asociados a las construcciones contemporáneas hasta una fase con abundante material de industria lítica y fragmentos cerámicos a mano de época calcolítica (UE 7: pre-arcillas). Sin lugar a dudas, los restos arqueológicos de mayor interés pertenecen a época romana, documentándose dos niveles correspondientes a una fase de necrópolis (UUEE 4 y 6). En total se han excavado 48 enterramientos pertenecientes a un momento cronológico que abarca desde época romana republicana (siglo I a. C.) hasta

4 En relación a los otolitos de corvina, recientes estudios han demostrado el carácter funerario y cultual de este tipo de evidencias en el suroeste peninsular (López Amador y Ruiz Gil, 20Io, 20I4), habiéndose puesto de relieve su uso como ofrendas en santuarios fenicio-púnicos y su aparición en contextos funerarios formando parte del ajuar de los difuntos. Por otra parte, sabemos que la corvina fue un pez frecuentemente capturado en la Antigüedad, tal y como se ha puesto de manifiesto en un trabajo de investigación reciente (Carrero, 2013), donde se han sistematizado, para el área del Círculo del Estrecho, todos los contextos en los cuales aparecen huesos de corvinas, desde el Neolítico hasta la Antigüedad Tardía. época imperial (finales del siglo i d. C. o comienzos del siglo II d. C.), documentándose una tipología de tumbas muy variada conforme a los ritos de la época, tanto de inhumación como de incineración (Bueno y Legupín, 2005).

Por lo que respecta a la presencia de instrumental pesquero, hemos inventariado una aguja de bronce (figura 4, I6) procedente de la UE 2I, que se corresponde con una tumba de incineración $\left(\mathrm{n}^{\mathrm{o}} 3\right)$ situada a una cota de -2,II m (Bueno y Legupín, 2005: 8). Sabemos que en este sector de la necrópolis gaditana los enterramientos de época imperial se depositaron sobre otros más antiguos de cronología republicana. De hecho la incineración $n^{\circ} 3$, junto con la $n^{\circ} 6$, había destruido una inhumación de época anterior - ${ }^{\circ}{ }_{2}$ - (Bueno y Legupín, 2005: 15), de ahí que hayamos planteado que la tumba que estamos analizando pertenezca a la fase altoimperial de la necrópolis. En lo que se refiere a la localización de esta pieza en la tumba, es posible que forme parte del ajuar funerario ya que las agujas constituyen uno de los elementos metálicos que suelen acompañar a los difuntos enterrados en esta necrópolis (Bueno y Legupín, 2005: 26).

\subsection{Calle Brunete 2}

Las excavaciones arqueológicas llevadas a cabo en el solar de la calle Brunete 2 (figura I, 7) han permitido documentar un sector de la necrópolis gaditana de época romano-republicana, localizándose un total de 27 tumbas, algunas de las cuales aparecieron revueltas por enterramientos posteriores. Lo verdaderamente interesante de este yacimiento lo constituye la aparición de una serie de estructuras murarias que conforman una calle así como de una alineación de ánforas que podrían estar delimitando el espacio funerario (Blanco, 1996: 4).

Por lo que respecta a la aparición de instrumental pesquero en este yacimiento, se han documentado dos agujas de bronce (figura 4, I7 y I8) procedentes de un mismo contexto arqueológico. El hallazgo de estas piezas tuvo lugar en la UE 52 que, junto con la UE 50 , se corresponde con una estructura cuadrada de 2,70 × 2,70 m localizada en la cuadrícula 23 y construida sobre la arena dunar (UE 2), habiéndose 
interpretado como un pequeño recinto funerario saqueado, con una orientación similar a la mayoría de los enterramientos que se han localizado (noroeste-sureste). En su interior se hallaron dos manchas de coloración negruzca correspondientes a sendas incineraciones (enterramientos 25 y 26), una de las cuales se extendía tanto por uno de los laterales no conservados del recinto como por la zona exterior del mismo -figura 6-(Blanco, I996: I4-I5).

\subsection{Calle García Carrera 9}

Los trabajos arqueológicos realizados en el $\mathrm{n}^{\circ} 9$ de la calle García Carrera -figura I, 8- (antiguas «Bodegas Abarzuza») han permitido documentar un importante sector de la necrópolis gaditana con una datación comprendida entre los siglos I a. C.-I d. C., registrándose 64 enterramientos así como una serie de estructuras arquitectónicas cuyo uso pudo haber estado vinculado con el propio cementerio y las actividades propias del mismo (Córdoba y Belizón, 2006: 70).

El enterramiento 63 se corresponde con una incineración en doble urna de vidrio y plomo (UUEE 374-378) depositada en el interior de una construcción de planta cuadrangular construida a través de pequeños sillarejos sin trabajar que han sido trabados mediante el uso de arena y arcilla roja, reforzados en los ángulos por piedras de mayor tamaño (Estructura 3: $\left.\mathrm{UE}_{35} 6\right)^{5}$. Para la construcción de esta estructura se ha abierto una fosa (UE 354 ) en cuyo interior apareció un anzuelo de bronce (Córdoba y Belizón, 2006: 66-67).

\subsection{Calle San Juan Bautista esquina a calle Marqués de Coprani}

En el año I997 se llevó a cabo una actividad arqueológica de urgencia en un solar ubicado en la calle San Juan Bautista esquina a la calle Marqués de Coprani (figura I, 9), en las inmediaciones del

5 Esta estructura podría haber sido expoliada en su esquina norte (UUEE 366-368). De la misma manera, esta construcción parece cortar, a su vez, los restos de un posible pozo del cual se ha conservado parte de su brocal (UUEE 357-362) (Córdoba y Belizón, 2006: 67). antiguo Cementerio de San José. Los resultados arqueológicos de esta intervención fueron de gran interés ya que se documentaron 33 estructuras de diferente cronología. Entre las de época romana destacan una serie de tumbas - tanto de incineración como de inhumación-, estructuras de carácter hidráulico - pileta ritual y pozos-, muros y fogatas. Los restos de época púnica, por su parte, pertenecen a una serie de estructuras murarias así como a un pozo (Molina, r997a).

De todas las tumbas excavadas nos interesa detenernos en la denominada «E.F. 2» que constituye una incineración primaria o de tipo bustum aparecida dentro de una estructura muraria de planta rectangular de cierta complejidad arquitectónica. A pesar de que la tumba había sido expoliada ya en época antigua, se hallaron los restos incinerados del difunto así como una serie de elementos de ajuar conformados por un cuenco de barniz rojo pompeyano, bordes de ánforas Dr. 7/ir y Dr. 20, una jarrita monoansada, clavos de bronce y de hierro, un fragmento de espejo de bronce, restos de un ungüentario de vidrio y dos agujas de hueso para el pelo. Durante la excavación del nivel de relleno (UE $5^{2}$ ) que colmataba el interior de la fosa abierta para la construcción de esta tumba (UE Io), apareció un contexto material datado en el siglo I d. C. Entre los restos cerámicos se han documentado un borde de jarrita con pico, varios ejemplares tanto de cerámica de barniz rojo julio-claudio como de TSI, destacando un fragmento con estampilla central con la marca $A T E I$, a lo que tenemos que sumar una pesa de red de cerámica. Junto al material cerámico, aparecieron objetos metálicos tales como cuatro botones de bronce y cuatro monedas (Molina, 1997a). La presencia de monedas de Gadir en este nivel de relleno se ha relacionado con un acto de sacralización de la inauguración de la fosa de construcción de la propia tumba (Arévalo y Moreno, 20I7: 5-7).

\subsection{Calle Santa Cruz de Tenerife 1 esquina a calle Santa María del Mar}

Los trabajos arqueológicos de urgencia realizados en el solar de la calle Santa Cruz de Tenerife I esquina a calle Santa María del Mar (figura I, ro) han 
A
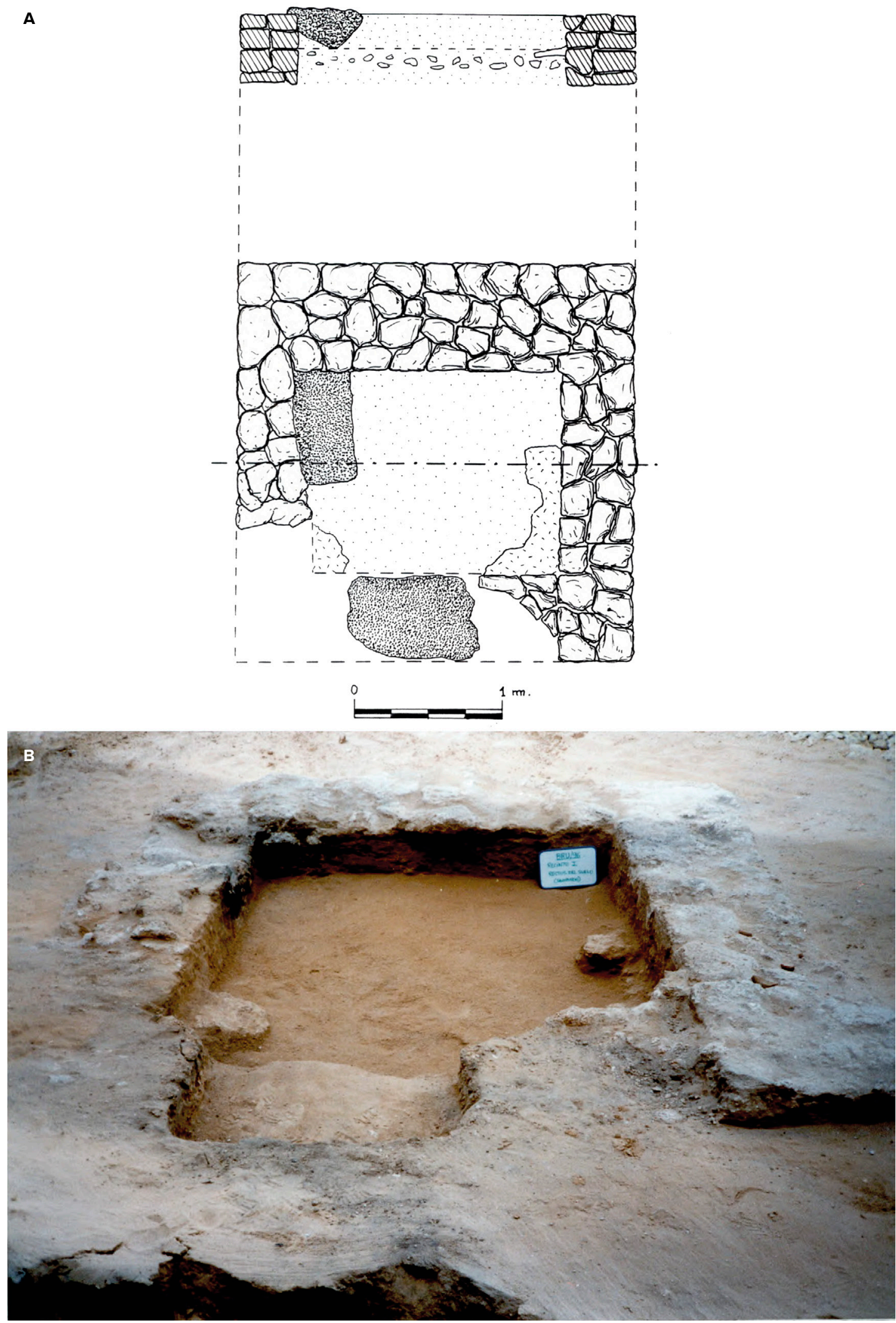

Figura 6. A. Dibujo de planta y alzado del recinto funerario documentado durante las excavaciones de la calle Brunete 2; B. Imagen de las estructuras murarias recién descubiertas y de las unidades estratigráficas asociadas

Figure 6. A. Plan and elevation drawing of the burial site documented during the excavations in calle Brunete 2; B. Imagen of the newly found Wall structure and the associated stratigraphic units (UE for its acronym in Spanish) 

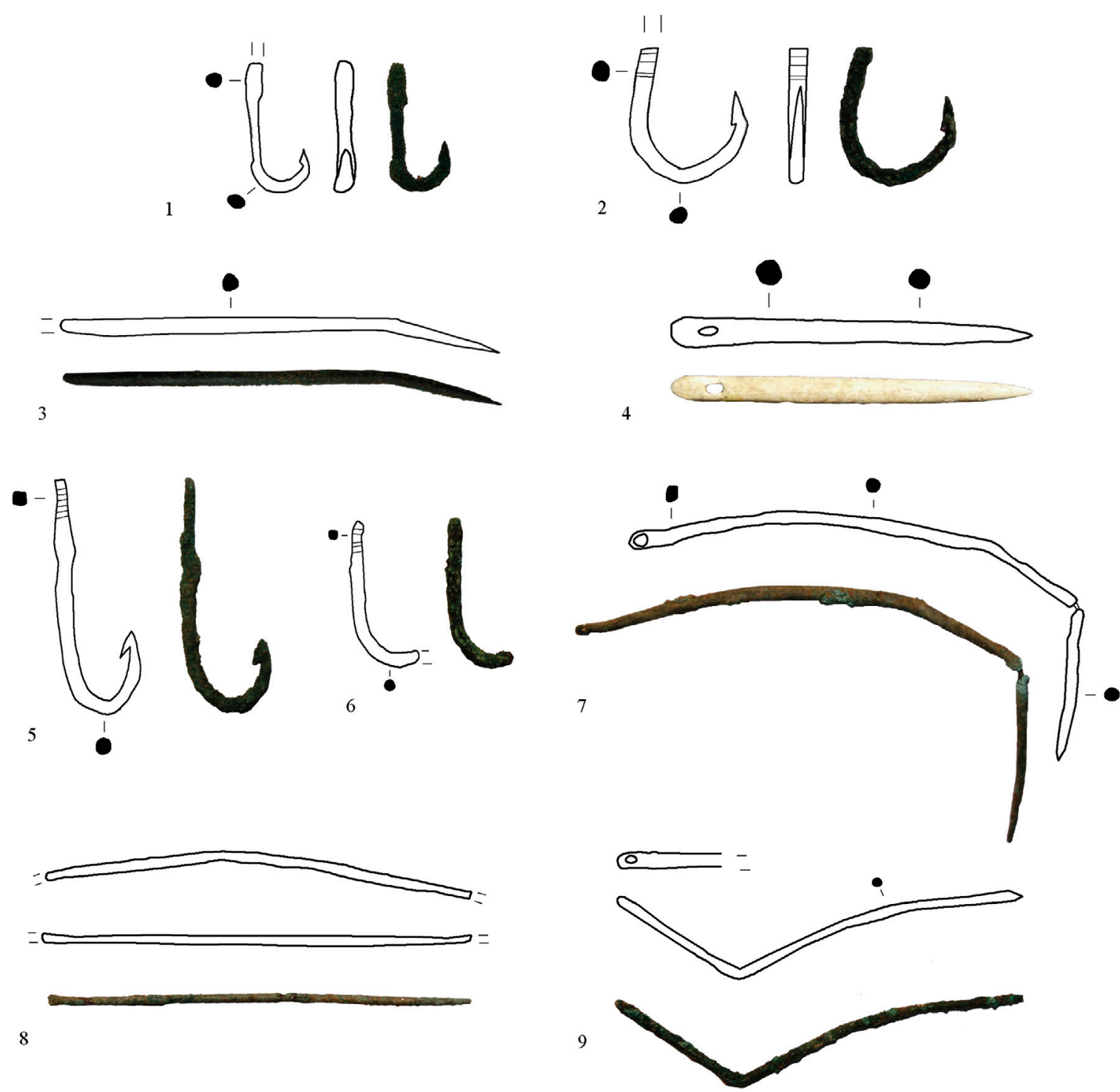

8

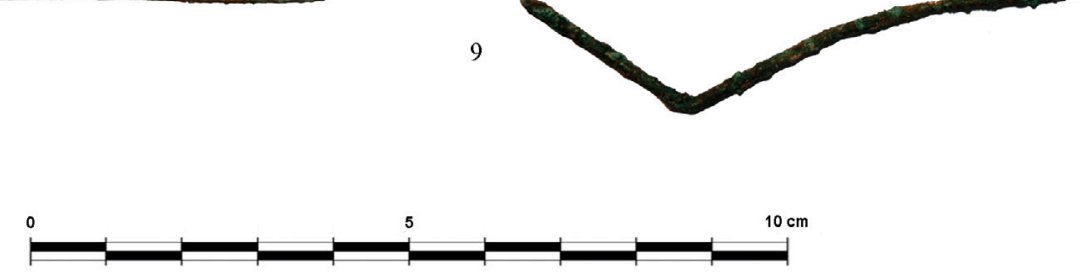

Figura 7. Artefactos pesqueros recuperados en las excavaciones de calle Santa Cruz de Tenerife 1 esquina a calle Santa María del Mar ( $n^{\circ 5} 1$ y 2: anzuelos; $n^{\circ} 3$ : aguja de bronce), calle Tolosa Latour ( $n^{\circ} 4$ : aguja de hueso) y Cuarteles de Varela -calle Marqués de la Ensenada y avenida de la Constitución 1812, fase II, 2000- ( $n^{\circ 5} 5$ y 6: anzuelos; $n^{\text {os }}$ 7-9: agujas de bronce)

Figure 7. Fishing devices recovered in the excavations in calle Santa Cruz de Tenerife 1 corner with calle Santa María del Mar (nos. 1 and 2: fishhooks; no. 3: bronze needle), calle Tolosa Latour (no. 4: bone needle) and Cuarteles de Varela - calle Marqués de la Ensenada and avenida de la Constitución 1812, 2nd phase, 2000 - (nos. 5 and 6: fishhooks; nos. 7-9: bronze needles)

permitido documentar un sector bastante importante de las necrópolis gaditanas. En total han aparecido 97 estructuras pertenecientes a diferentes momentos históricos, que abarcan desde época púnica a la modernidad, habiéndose registrado 80 tumbas, siete estructuras murarias, seis fosas con material de desecho, dos fosas de estructuras funerarias, un pozo y un horno (Molina, 1997b).
De esta intervención se han recuperado algunos instrumentos de pesca, concretamente dos anzuelos (figura 7 , г y 2) y una aguja de bronce (figura 7,3 ), procedentes de diferentes contextos arqueológicos. En relación al anzuelo $n^{\circ}$, sabemos que su hallazgo tuvo lugar en la UE 2 que constituye un nivel de arena dunar holocénica sobre el que se excavan las tumbas tardopúnicas y romanas y cuyo período de 
formación se ha establecido entre los siglos III a. C. y i d. C. (Molina, I997b: 8). Por su parte el anzuelo $\mathrm{n}^{\mathrm{o}} 2$ procede de un contexto cronológicamente más preciso, concretamente de la UE i78 que se corresponde con una unidad estratigráfica de la que apenas tenemos información a excepción de que se trata de un nivel fechado entre los siglos i y in d. C., localizado entre la UE i ${ }^{6}$ y la UE 2 (Molina, I997b: 9).

De las tres piezas inventariadas tan solo una de ellas sabemos que apareció asociada a una estructura funeraria. Nos referimos a la única aguja de bronce recuperada (figura 7,3 ), cuyo hallazgo tuvo lugar en la «E.F. 34» que constituye una incineración en fosa simple de tipo bustum sin ningún tipo de protección, fechada en el siglo I d. C. Se trata de un enterramiento localizado en la cuadrícula i5 a una cota de $-50 \mathrm{~cm}$, llegando hasta una profundidad de $-90 \mathrm{~cm}$. Por lo que respecta al ajuar funerario, aparece un borde de cuenco de cerámica común romana, un borde de jarrita, un clavo, una pequeña lámina de bronce así como la aguja broncínea que traemos a colación (Molina, I997b: I6).

\subsection{Calle Tolosa Latour 1987}

Las excavaciones llevadas a cabo en un solar de la calle Tolosa Latour de Cádiz (figura I, II) durante el año I987 permitieron documentar un importante sector de la necrópolis gaditana. Los enterramientos se distribuían en dos sectores perfectamente delimitados: en la zona oeste y sobre todo en su mitad norte se construyeron las tumbas de las épocas fenicia y púnica, mientras que en la zona este aparecen las tumbas tardopúnicas y romanas (Perdigones y Muñoz, 1990: 59). Sabemos de la aparición de una aguja de coser de hueso (figura 7,4 ) en la tumba 44 (cuadrícula D-6), que corresponde a una tumba de incineración en fosa simple excavada en la arena parda o arcilla (Nivel 2-3), sin protección alguna, de época romana (Perdigones y Muñoz, I990: 67).

6 Nivel moderno con una potencia estratigráfica de 40/50 cm (Molina, 1997: 8).

\subsection{Cuarteles de Varela (calle Marqués de la Ensenada y avenida de la Constitución 1812, Fase II, 2000)}

Las excavaciones que se realizaron en este solar (figura I, I2) han permitido documentar tres grandes fosas pertenecientes a un sector de la necrópolis gaditana, cada una de ellas formadas por un determinado grupo de enterramientos. En relación a la Fosa I (Zanjas 5 y 6), de donde proceden dos anzuelos (figura 7,5 y 6) así como una aguja de bronce (figura 7,7 ), constituye el conjunto de enterramientos más interesante, estando conformada por 13 tumbas de inhumación. La secuencia estratigráfica de la Fosa r se compone de cuatro niveles (UUEE 8a, 6a, ro y 8b). Los instrumentos de pesca se recuperaron en la UE io, que se trata de un nivel de arena castaña fina de $38 \mathrm{~cm}$ de potencia estratigráfica con abundante vertido de materiales arqueológicos, sobre todo de tipo cerámico ${ }^{7}$, habiéndose relacionado con los recipientes de los banquetes funerarios (Blanco, 2000: 45). Los enterramientos de la Fosa i pertenecen al menos a dos o tres generaciones diferentes, fechados entre finales del siglo in a. C.y principios del siglo i a. C. (Blanco, 2000: 45). La doctora Ana Niveau de Villedary, en su estudio sobre la cerámica de tipo Kouass gaditana (Niveau de Villedary, 2oora), señala que en este solar aparecieron grandes bolsadas de materiales arqueológicos que pueden adscribirse cronológicamente a la primera mitad del siglo in a. C. ${ }^{8}$ —ánforas, cerámica común y vajilla fina de mesa campaniense A y últimas producciones de Kouass(Niveau de Villedary, 200ra: 4I9).

En esta misma fosa apareció una aguja de bronce (figura 7,8 ) en la tumba I4 (UUEE $\left.{ }_{52} / 54\right)^{9}$, tratándose de una inhumación en fosa simple excavada en la arcilla rojiza cuya cubierta se halla destruida en

7 En la ficha de inventario del Museo de Cádiz $\left(n^{\circ} 24450\right.$ para los anzuelos y n ${ }^{\circ} 26$ roo para la aguja), esta unidad estratigráfica se relaciona con un vertido/relleno de escombrera. 8 En la ficha de inventario de los anzuelos (Museo de Cádiz, $n^{\circ} 24450$ ), este contexto se ha fechado precisamente en el siglo II a. C.

9 Este contexto se ha datado en el siglo ir a. C. según la ficha de inventario de la pieza del Museo de Cádiz (nº 2443I). 
su parte central debido a que fue expoliada. Entre los escasos restos aparecidos en este enterramiento se localizó parte de un cráneo así como evidencias de húmeros y pies in situ, encontrándose, además, otros restos óseos revueltos. Todo ello pertenecía a una persona adulta cuya talla sería de I,64 m, estando su cuerpo colocado decúbito supino en posición estirada y depositado sobre una capa de tierra castaña oscura, sin tocar la arcilla geológica. En la cabecera del difunto se halló la aguja de bronce que traemos a colación, habiéndose considerado, a pesar de que la pieza se halló revuelta entre la tierra, como un elemento de ajuar de la tumba (Blanco, 2000: 54).

En lo que se refiere a la Fosa 3 (Zanja 8), donde se recuperó otra aguja de bronce (figura 7,9 ), sabemos que en su interior se han documentado tres enterramientos de inhumación (Blanco, 2000: 67). La pieza que traemos a colación procede de la $\mathrm{UE}_{5 \mathrm{I}}$ que, según la referencia que hemos encontrado en la ficha de inventario del Museo de Cádiz ( $\mathrm{n}^{\circ}$ 24454), debe corresponderse igualmente con un vertido a modo de escombrera.

\subsection{Cuarteles de Varela (avenida Andalucía s/n.)}

Durante los meses de septiembre de 2002 y junio de 2003 se llevó a cabo una nueva fase de intervención arqueológica en los terrenos pertenecientes a los antiguos cuarteles de Varela (figura I, I3), motivada esta vez por la construcción de un aparcamiento subterráneo y la posterior urbanización del espacio libre dejado en superficie. Las excavaciones realizadas en este inmenso solar permitieron exhumar 390 enterramientos pertenecientes a diferentes momentos de uso de las necrópolis de época fenicio-púnica y romana así como I6 estructuras de muy variada naturaleza entre las que destacan una serie de estancias habitacionales agrupadas en torno a un atrio; cuatro hornos; una gran fosa - posiblemente de carácter ritual- con abundante material cerámico de tipo Kouass; varias fosas a modo de vertedero de época romana con fragmentos anfóricos; numerosas ánforas hincadas formando algunos grupos de alineaciones; y de gran interés ha sido también la aparición de una serie de estructuras correspondientes al sistema de captación y almacenamiento de agua (Bejarano, 2003: 2-3).

Durante las labores de campo se recuperaron una serie de instrumentos de pesca, entre los que se encuentran anzuelos simples (figura 8, I-4), agujas de bronce (figura 8, 5-9) y pesas de red, cuya aparición en este yacimiento arqueológico se ha relacionado con la frecuente dispersión de materiales, dentro de la Unidad Matriz III (a y b), como resultado del sistemático saqueo al que se vio sometida la necrópolis (Bejarano, 2003: 28).

El nivel III (U.M. III), que ocupaba la totalidad del solar, constituye el primer nivel arqueológico de época romana y estaba formado por un paquete estratigráfico continuo de tierra de escasa compacidad, color ocre y castaño claro, con vetas rojizas, amarillentas y grises en algunas zonas. Dentro de esta unidad estratigráfica se ha diferenciado entre el nivel IIIa, afectado por las cimentaciones de los antiguos cuarteles, y el nivel IIIb, situado justo debajo, que no ha sufrido alteraciones por las construcciones militares. Es en este nivel III donde se localizan los arranques de los alzados de la mayoría de las estructuras documentadas así como las escasas tumbas romanas de los momentos más tardíos —siglos III-IV- (Bejarano, 2003: 2I). De todo el instrumental pesquero que hemos inventariado sabemos que, con seguridad, el anzuelo $\mathrm{n}^{\circ} 3$ así como los agujas nos 8 y 9 de la figura 8 proceden de este nivel arqueológico.

Por otro lado, hemos podido determinar que uno de los anzuelos (figura 8, 4 ) se recuperó en el denominado nivel IIIb-IV (= al nivel IIIc), situado bajo la U.M. III, que se corresponde con un estrato de arena de duna poco compacta de unos $20 \mathrm{~cm}$ de potencia estratigráfica, también relacionado con la fase romana del yacimiento (Bejarano, 2003: 2I).

Del resto de los instrumentos de pesca, las fichas de inventario del Museo de Cádiz tan solo nos informan acerca de las cuadrículas donde fueron encontrados, sin hacer mención expresa al contexto arqueológico, si bien deducimos que debieron haber sido localizados en el nivel III, tal y como se explica en la memoria final de esta intervención (Bejarano, 2003: 28). 


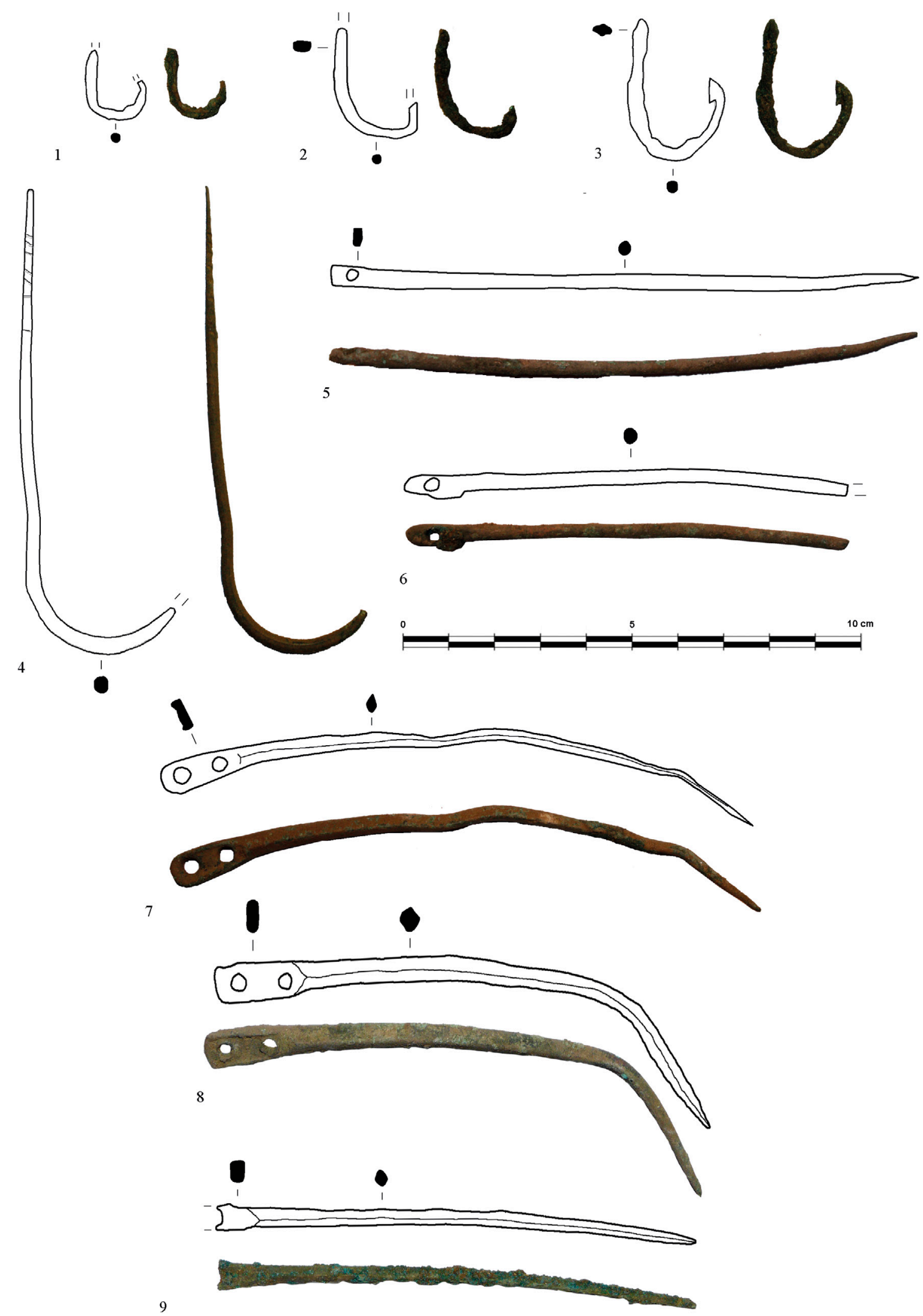

Figura 8. Instrumental de pesca procedente de los Cuarteles de Varela -avenida Andalucía s/n.- (nos 1-4: anzuelos; $\mathrm{n}^{\mathrm{os}} 5$-9: agujas de bronce)

Figure 8. Fishing instruments recovered in Cuarteles de Varela - avenida Andalucía - (nos. 1-4: fishhooks; nos. 5-9: bronze needles) 


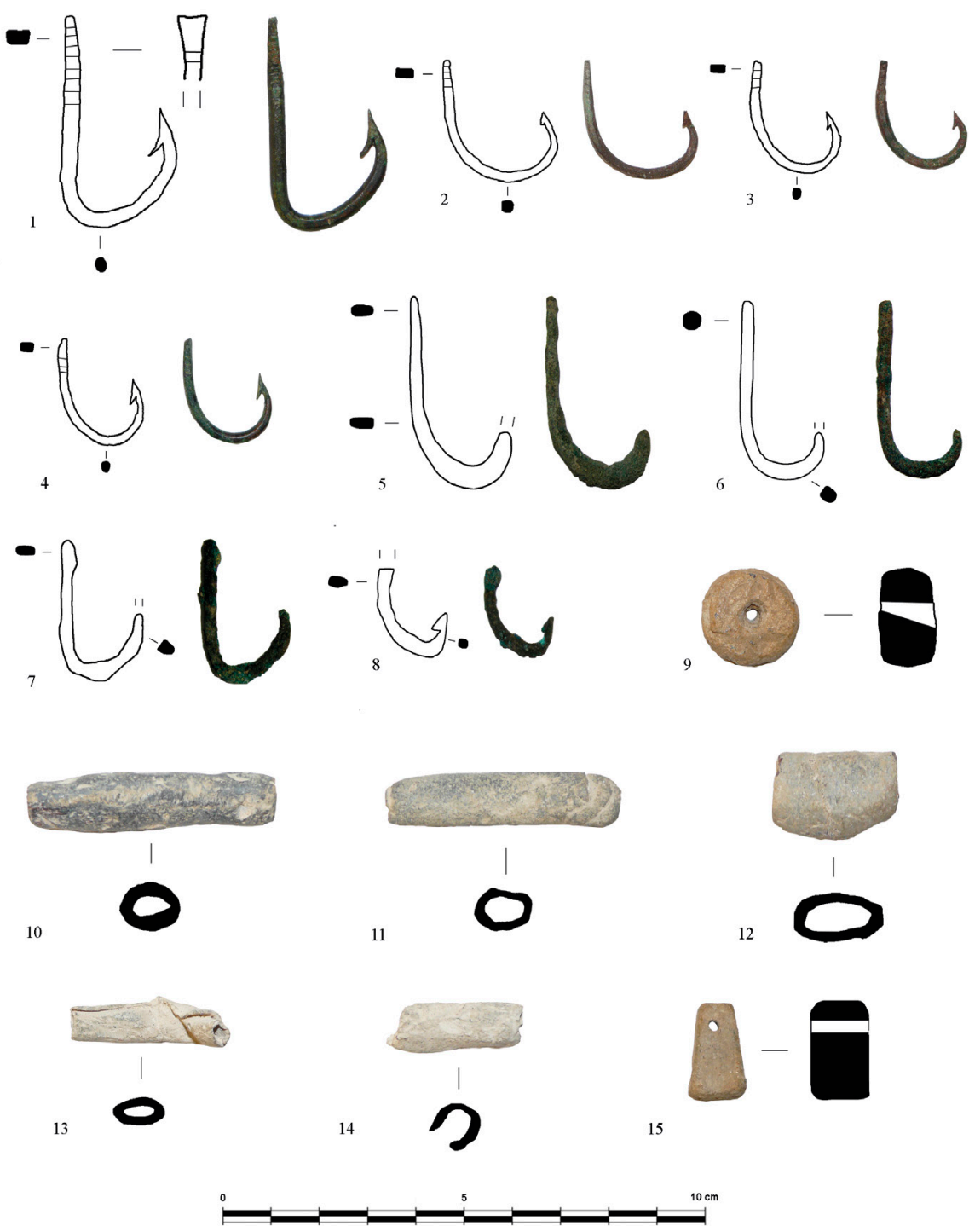

Figura 9. Utensilios de pesca recuperados en el solar correspondiente al futuro Palacio de la Justicia (nos 1-8: anzuelos; $n^{\circ}$ 9: pesa de plomo anular; $n^{\circ s}$ 10-14: pesas de plomo laminares enrolladas; $n^{\circ} 15$ : pesa de plomo troncopiramidal)

Figure 9. Fishing tools recovered in the site where the future Palacio de Justicia will be located (nos. 1-8: fishhooks; no. 9: ring-shaped fishing weight; nos. 10-14: laminated fishing weights; no. 15: pyramidal trunk-like fishing weight)

\subsection{Palacio de la Justicia}

Entre los meses de agosto de 2005 y marzo de 2006 se realizó una intervención arqueológica en un solar destinado a albergar la «Ciudad de la Justicia» (figura I, I4), documentándose un total de I94 tumbas pertenecientes tanto a época tardopúnica y republicana como a época altoimperial, a lo que tenemos que sumar la aparición de cuatro pozos, siete piletas, tres fosas excavadas en la arcilla rellenas de materiales arqueológicos, una estructura hidráulica así como varias construcciones que debieron servir $\mathrm{pa}-$ ra delimitar espacios dentro de la propia necrópolis (Sibón et alii, 2010).

En las excavaciones llevadas a cabo en este inmenso solar se ha recuperado un interesante lote de instrumental pesquero conformado por 23 piezas entre las que se encuentran anzuelos de bronce (figura 9, I-8), pesas de plomo de variada tipología — anular (figura 9, 9), laminares enrolladas (figura 9, IO-I4) y troncopiramidal (figura 9, I5) - , un artefacto curvo de hierro con filo cortante (figura Io) y agujas metálicas (figura II, I-7). 


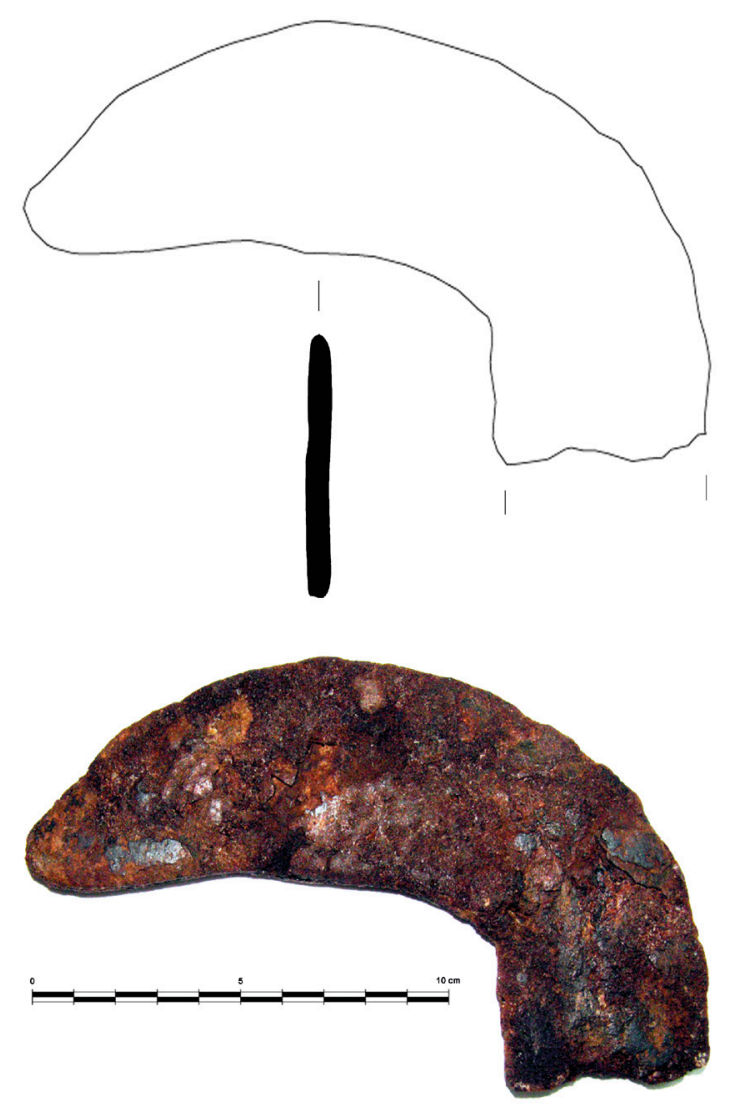

Figura 10. Artefacto curvo de hierro con filo cortante (Palacio de la Justicia)

Figure 10. Curved iron device with cutting edge (Palacio de la Justicia)

A pesar de que se desconocen los contextos arqueológicos donde se produjeron los hallazgos de cada una de estas piezas, contamos con algunos datos que nos permiten relacionarlas con las fosas excavadas en la arcilla. Por lo que respecta a la Fosa $n^{\circ}$ I (UE 57 , cuadros B-2 y B-3), datada en época romana altoimperial, se caracteriza porque el nivel de relleno depositado en su interior es variado y multiforme, con arenas de diversa coloración. Los materiales arqueológicos que se han recuperado son principalmente de tipo cerámico si bien también están presentes los vidrios, el material óseo (agujas), las terracotas y las monedas, habiéndose recuperado un importante grupo conformado por 62 ejemplares. Sabemos que además de las monedas, han aparecido otros materiales metálicos de bronce tales como anzuelos y agujas a lo que tenemos que sumar abundantes pesas de plomo con fines pesqueros (Sibón et alii, 2010: 153). De la misma manera, en la memoria final de la excavación, se menciona que en la Fosa ${ }^{\circ}$ I se documentan

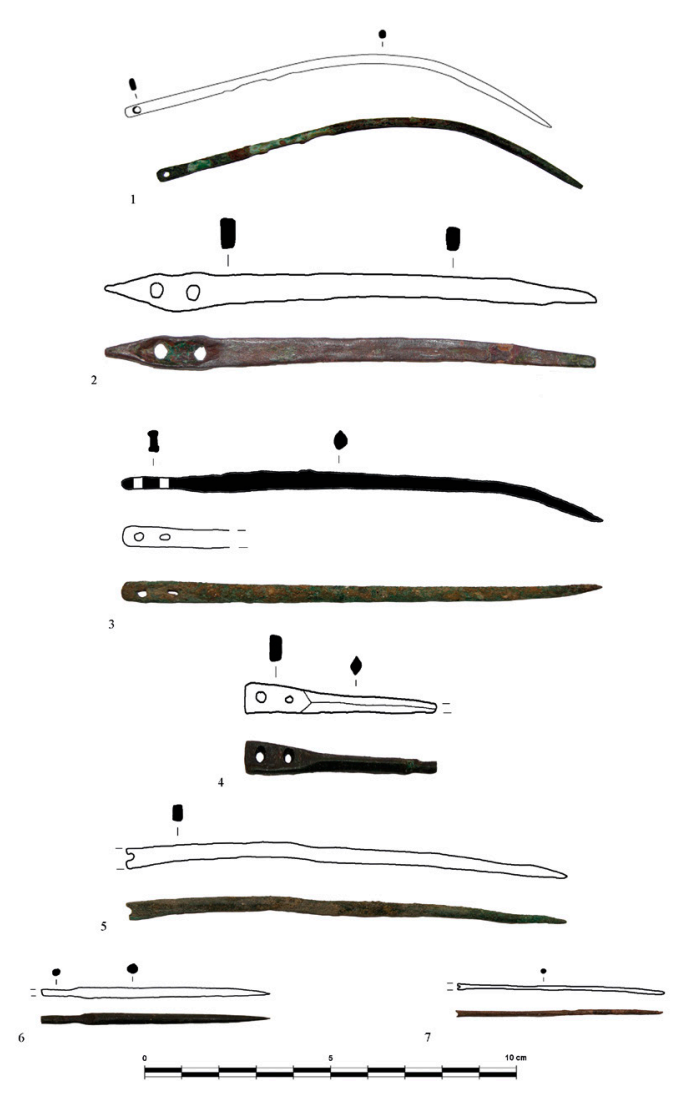

Figura 11. Agujas metálicas procedentes de las excavaciones llevadas a cabo en el Palacio de la Justicia

Figure 11. Metal needles from the excavations carried out in the Palacio de la Justicia

un total de seis anzuelos, dos pesas de plomo, siete láminas de plomo enrolladas y dos agujas de bronce destinadas a actividades de pesca (Sibón, 2006a: 170).

En lo que se refiere a la Fosa no 2 (UE 236, cuadro $\mathrm{F}-2$ ), se trata realmente de un hoyo excavado en la tierra de poca profundidad $y$ forma alargada $(3,20 \mathrm{~m}$ de longitud $\times$ I $\mathrm{m}$ de ancho), vinculándose a un grupo de enterramientos cercanos. El material arqueológico hallado en su interior es fundamentalmente de tipo cerámico, estando representadas las ánforas, la cerámica común grosera y fina, la vajilla tipo «Kuass» y el barniz negro, arrojando un marco cronológico muy preciso en torno a finales del siglo III-comienzos del siglo iI a. C. (Niveau de Villedary, 20I0: 194-199).

La Fosa no 3 (UE Ir9, cuadro B-I), por su parte, presenta una forma cuadrada con unas dimensiones de aproximadamente $2,5 \mathrm{~m}$ de lado y una profundidad de I,5 $\mathrm{m}$. El nivel de relleno que la amortiza está conformado por tierras de coloración gris oscuro como resultado de la descomposición orgánica, con 
algunas vetas de tonalidad anaranjada. Esta estructura negativa se halla rellena de fragmentos cerámicos, habiéndose documentado un mayor número de materiales que en el caso anterior (Fosa no 2 ) si bien la cronología que ha deparado el registro cerámico de la Fosa no 3 se sitúa también a finales del siglo III a. C. (Niveau de Villedary, 2010: I87-194).

La aparición de instrumental pesquero en estas dos últimas fosas es más incierta que en el caso de la Fosa $n^{\circ}$ I, si bien hemos encontrado algunas referencias ${ }^{10}$ en una serie de estudios centrados en las fosas $\mathrm{n}^{\text {os }} 2$ y 3 , donde se menciona explícitamente el hallazgo de instrumenta utilizados en la vida cotidiana tales como agujas, anzuelos y pesas (Niveau de Villedary, 2010: 228).

\subsection{Plaza Asdrúbal 1985}

En la plaza Asdrúbal de Cádiz se han acometido diferentes actividades arqueológicas durante la década de los años 80 y 90 del pasado siglo (1983/r984, I985, I986, I988 y I997/I998), las cuales han permitido documentar una serie de restos pertenecientes a las necrópolis púnica y romana así como diversas estructuras de producción y fosas relacionadas con factorías de salazones ${ }^{11}$ (Bernal-Casasola et alii, 20I4: 205).

Durante la campaña de 1985 (figura I, I5) se recuperaron una serie de instrumentos de pesca procedentes de diferentes contextos funerarios, tanto anzuelos (figura I2, I-6) como agujas de bronce (figura I2, 7 y 8). En el caso de los anzuelos, algunos de ellos proceden de la tumba $6^{12}$ (figura I2, 3-6), que se corresponde con una inhumación en fosa simple

10 En el tomo III de la memoria final de las excavaciones se incluye una addenda titulada «Estudio de Fosa ritual púnica (Fosa 2 del sector S-W) y tardopúnica (Fosa 3 del sector N-E)», redactada por Ana $\mathrm{M}^{\mathrm{a}}$ Niveau de Villedary, donde se menciona la aparición de agujas, anzuelos y pesas (Sibón, 2006b: 83).

11 La bibliografía sobre las excavaciones realizadas en la plaza Asdrúbal de Cádiz es muy amplia. Remitimos a la síntesis de Ángel Muñoz (Muñoz, 2012: 46-58) para conocer resumidamente la problemática de este yacimiento.

12 Entendemos que se trata de la tumba 6 de la zona $\mathrm{F}$ ya que, según la planimetría de la excavación (Perdigones y Muñoz, I987: 59, fig. I), en la zona $\mathrm{E}$ tan solo aparecieron cinco enterramientos (tumbas $\mathrm{I}-5$ ). muy estrecha excavada en el nivel $\mathrm{Id} / 2$ a (nivel púnico de uso industrial en la zona) y cuya parte inferior alcanza el nivel 2b/3 (nivel de paleosuelos rojos y roca arenisca). En este sentido, recientemente se ha defendido que todos los materiales arqueológicos, tanto artefactos como ecofactos, hallados en esta tumba deben ponerse en relación con la rotura de los niveles industriales para la excavación de la fosa funeraria (toda la problemática en Bernal-Casasola et alii, 20I4), poniéndose en duda, por lo tanto, la idea de que puedan corresponder a ofrendas o rituales funerarios (Niveau de Villedary y Abia, 20I4). Estos niveles industriales corresponden a estratos deposicionales de matriz arenosa y coloración grisáceo-negruzca en los cuales han aparecido restos de ictiofauna, malacofauna y cerámicas. Los materiales cerámicos asociados a los depósitos contiguos a la tumba 6 están representados por fragmentos de ánforas Cádiz $\mathrm{A}_{4} \mathrm{a}-\mathrm{A}_{4} \mathrm{c}-\mathrm{d} /$ Serie Ir y I2 de Ramon, cuenco carenado, fragmento de skyphos, entre otros, los cuales han permitido datar la tumba a inicios del siglo Iv a. C. (Bernal-Casasola et alii, 2014: 217-218). Por todo lo que llevamos dicho, es posible que la aparición de este grupo de anzuelos en la tumba 6 pueda explicarse a través del mismo proceso postdeposicional, debiéndose relacionar su origen con los niveles industriales asociados a la factoría de salazones, situada en las proximidades al solar objeto de estudio.

Realmente, el caso que acabamos de exponer pone de relieve la problemática contextualización de aquellos materiales que proceden de yacimientos que presentan un carácter doble: industrial y funerario. Las numerosas intervenciones arqueológicas de carácter urbano que han venido realizándose desde los años 80 , han demostrado que determinados sectores de Gadir/Gades, cuya vinculación con la industria pesquero-conservera está bien constatada desde finales del siglo vi a. C., constituyen espacios compartimentados donde factorías de salazones y necrópolis conviven, en algunos casos, o se superponen unas a otras, en otros casos. Esta dualidad espacial ha sido tratada en un trabajo donde se analizan con riguroso lujo de detalles todos los yacimientos gaditanos vinculados a la industria de la salazón desde el siglo II a. C. hasta el siglo vi d. C. (Expósito, 2007). 

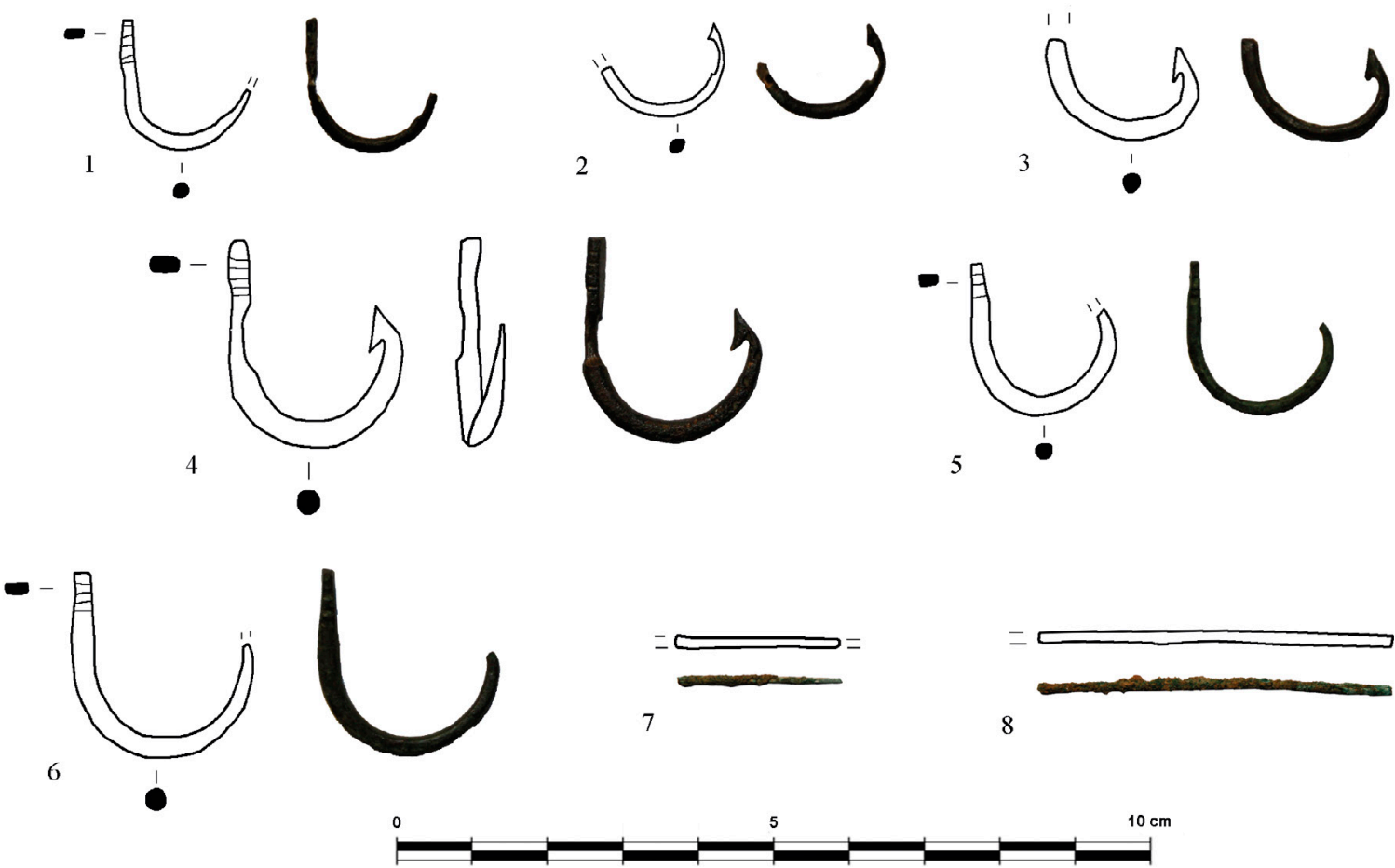

Figura 12. Instrumentos de pesca descubiertos en la campaña de 1985 llevada a cabo en plaza Asdrúbal (nºs 1-6: anzuelos; $\mathrm{n}^{\circ \mathrm{s}} 7$ y 8 : agujas de bronce)

Figure 12. Fishing instruments discovered in the 1985 campaign carried out in plaza Asdrúbal (nos. 1-6: fishhooks; nos. 7 and 8: bronze needles)

También de la campaña de 1985 proceden otros anzuelos de cuyo contexto arqueológico contamos con menos información. Nos referimos a los anzuelos $n^{\text {os }}$ I y 2 de la figura I2, ambos procedentes de la tumba 7 de la zona F, desconociéndose ante qué tipo de enterramiento nos encontramos. Sin embargo, atendiendo a la planimetría de la fase funeraria del yacimiento publicada en los años 80 del pasado siglo (Perdigones y Muñoz, I987: 59, fig. I), es posible que se trate de una estructura integrada en un complejo de cuatro tumbas en cistas de sillería - figura I3 (tumbas 5, 7, 8 y 9) depositadas en una fosa excavada en las arcillas rojizas (paleosuelos rojos) y en la roca geológica, relacionadas posiblemente por parentesco o etnia (Bernal-Casasola et alii, 20r4: 216). Es posible que el hallazgo de estos anzuelos en la tumba 7 esté relacionado igualmente con procesos post-deposicionales debido a la realización de una fosa haliéutica (fosa $\mathrm{F}$ de la zona $\mathrm{F}$ ) coincidente con sendas cabeceras de las tumbas 7 y 8 - figura $\mathrm{I}_{3}$ - (Muñoz y De Frutos, 2009: 85, fig. 2).
Por último, sabemos de la aparición de dos agujas de bronce (figura I2, 7 y 8) en la tumba 2 de la zona E. De la planimetría de la excavación (figura 13) deducimos que se trata de una inhumación en fosa simple que no parece haber sido afectada por ninguna de las fosas haliéuticas vinculadas con los saladeros púnicos, las cuales parecen concentrarse sobre todo en la zona $\mathrm{F}$ del yacimiento (Muñoz y De Frutos, 2009: 85, fig. 2).

\subsection{Plaza Asdrúbal 1997-1998}

Las actividades arqueológicas realizadas en la plaza Asdrúbal durante los años 1997 y 1998 (figura I, I6) permitieron documentar un espacio con doble funcionalidad datado entre los siglos IV a. C.-II d. C. Por un lado, se localizó un sector de la necrópolis gaditana conformado por 1o7 enterramientos cuya datación se ha establecido atendiendo a la tipología de las tumbas, abarcando desde el siglo iv a. C. hasta los siglos I-II d. C. Por otro lado, apareció un nuevo 


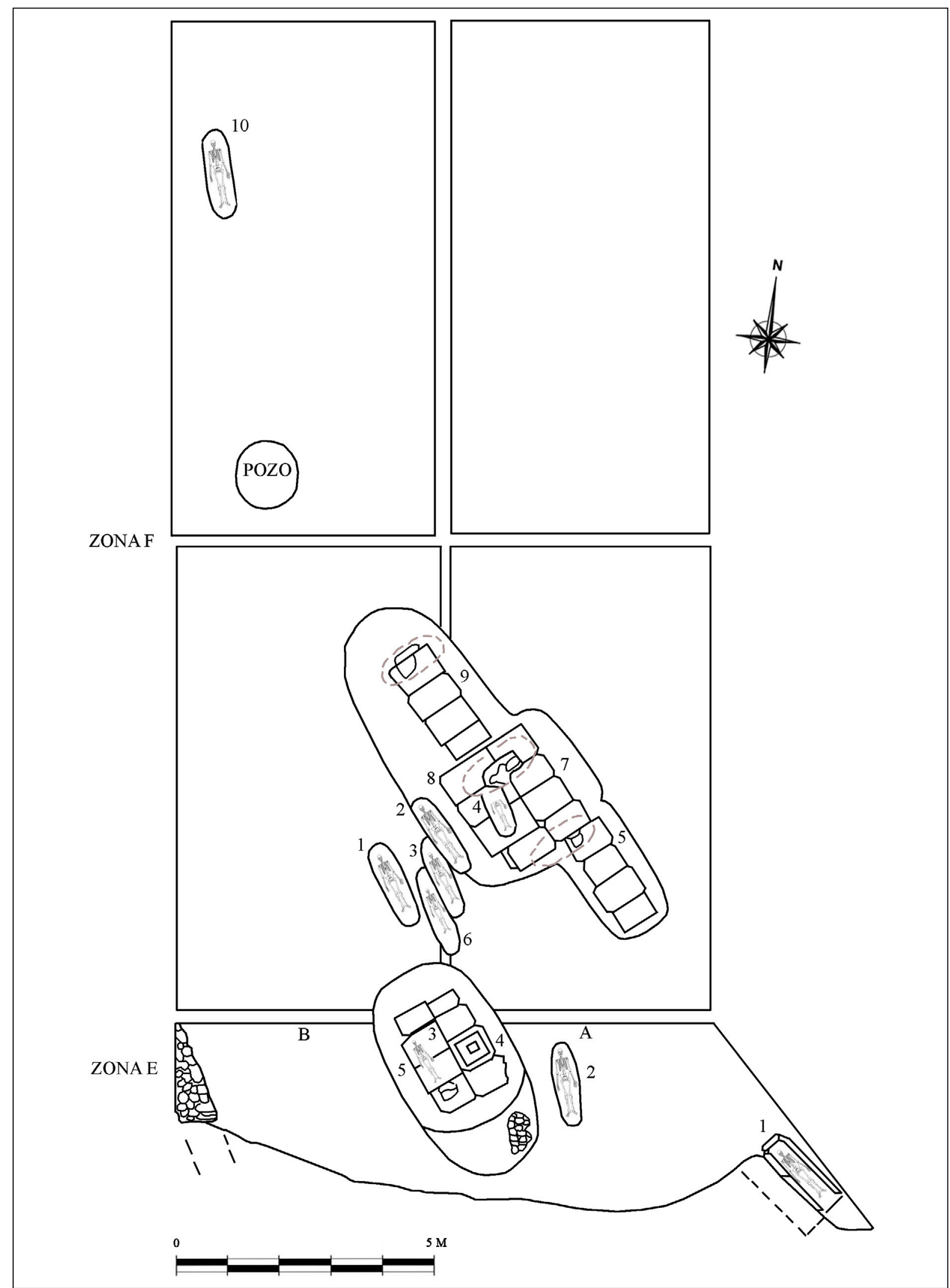

Figura 13. Planimetría de las zonas E y F de los restos exhumados durante las excavaciones en plaza Asdrúbal —campaña de 1985- (elaboración propia a través del original de Perdigones y Muñoz, 1987: 59, fig. 1)

Figure 13. Planimetry of the zones $\mathrm{E}$ and $\mathrm{F}$ of the exhumed remains during the excavations in plaza Asdrúbal -1985 campaign (own elaboration following the original one by Perdigones and Muñoz, 1987: 59, fig. 1) 

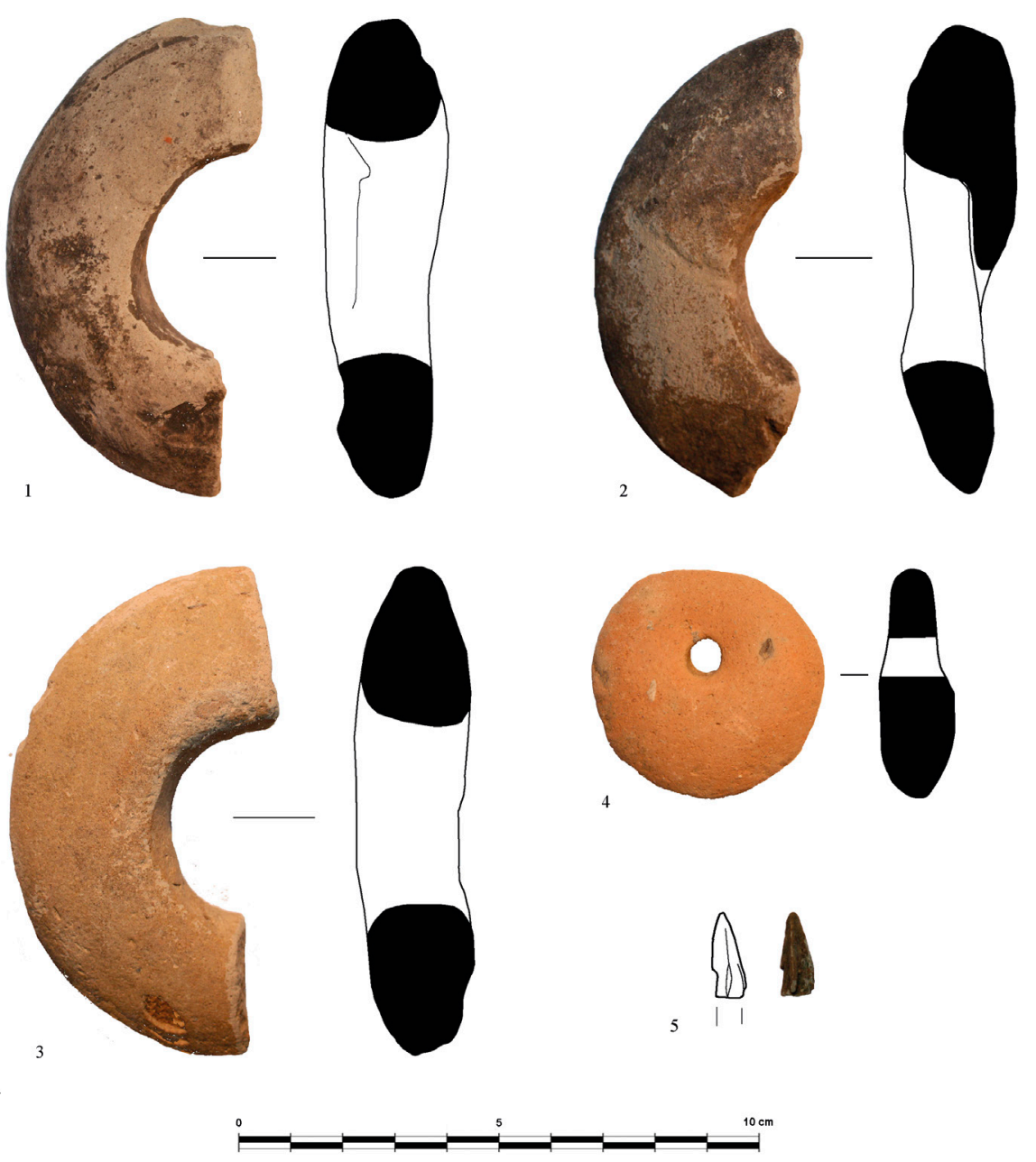

Figura 14. Diferentes modelos de pesas ( $n^{\circ s} 1-3$ : discoidales; $n^{\circ} 4$ : recortada sobre fragmento cerámico) y punta de arpón ( $\left.n^{\circ} 5\right)$ procedentes de plaza Asdrúbal (campañas de 1997-1998)

Figure 14. Different models of fishing weights (nos. 1-3: disc-shaped weight; no. 4: weight cut over ceramic fragments) and tip of a spear (no. 5) from plaza Asdrúbal (1997-1998 campaigns)

sector del conjunto industrial pesquero-conservero, ampliamente documentado en campañas anteriores, cuyo período de actividad oscila entre finales del siglo in o principios del siglo II a. C. y mediados del siglo i d. C. ${ }^{13}$.

En el transcurso de estas excavaciones aparecieron un número considerable de instrumentos de pesca, habiéndose inventariado un total de I39 piezas, siete de las cuales proceden de contextos funerarios: cuatro pesas de cerámica discoidales (figura I4, I-3; figura 15, I), un pondus (figura 15, 2), una pesa de cerámica recortada (figura I4, 4) y una punta de arpón (figura I4, 5). Algunas de estas pesas (figura I4, I y 2; figura 15, 2) proceden de la UE $477^{14}$ que, junto con las UUEE 478 y 479 , constituye la tumba $n^{\circ}$ 6r, incluida dentro del grupo de enterramientos de época tardopúnica y romana republicana (siglos III-I a. C.). Se trata de una inhumación en fosa simple con una cubierta de sillarejos de roca caliza para la cual se ha excavado una fosa - con una orientación noroeste-sureste- en la arcilla rojiza hasta alcanzar la marga, donde se ha depositado el
13 Estos datos han sido extraídos del informe titulado «Síntesis de las excavaciones arqueológicas realizadas en la Plaza Asdrúbal esquina con el Paseo Marítimo» ( $\mathrm{n}^{\circ}$ de expediente:A-I/92 - Io6 A), depositado en la Delegación de Cultura de Cádiz.
14 En la etiqueta de la bolsa donde aparecieron dos de estas piezas (figura I4, I y 2) aparece la siguiente referencia: «fosa negra» (cuadros A8/9). 

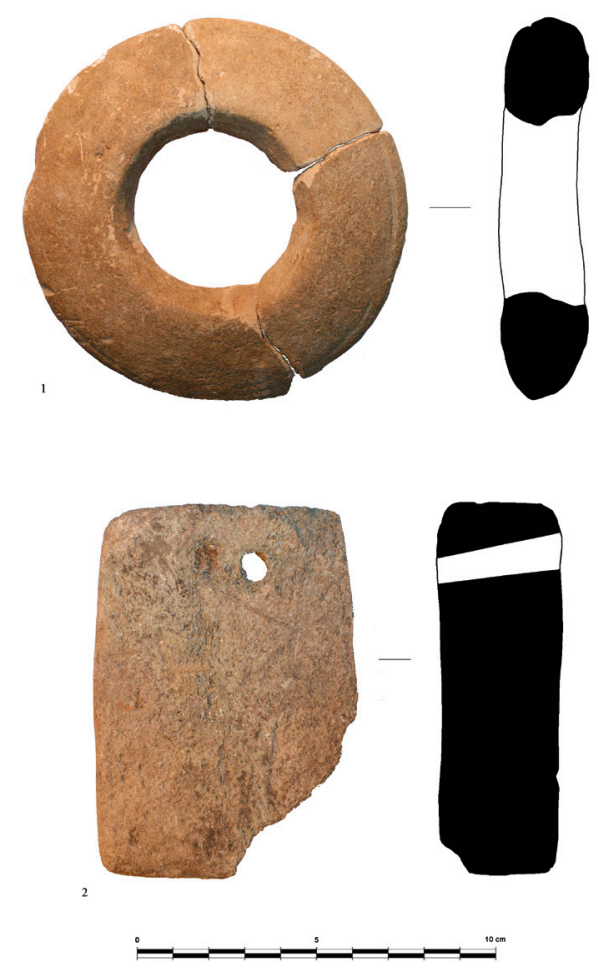

Figura 15. Pesa discoidal ( $\left.n^{\circ} 1\right)$ y pondus troncopiramidal $\left(n^{\circ} 2\right)$ procedentes de plaza Asdrúbal (campañas de 1997-1998)

Figure 15. Disc-shaped weight (no. 1) and pyramidal trunk-like pondus (no. 2) from plaza Asdrúbal (1997-1998 campaigns)

cadáver. El inhumado se corresponde con un individuo adulto colocado decúbito supino, encontrándose su cuerpo muy destruido por la acidez del terreno, conservándose parte del cráneo con los brazos y piernas estiradas y con las manos sobre la pelvis. Como elementos de ajuar ha aparecido un collar a la altura del pecho así como dos pendientes de plata y un anillo de bronce con pan de oro de chatón plano entre los dedos de la mano izquierda (Blanco, I998: 51-52).

Otro de los contextos funerarios donde han aparecido materiales pesqueros se corresponde con la UE 268 (cuadro B8) de donde proceden dos pesas de cerámica de tipo discoidal (figura I4, 3; figura 15, I). La UE 268 (tumba no ${ }^{\text {I4 }}$ ) se trata de una incineración en urna de cerámica incluida dentro del grupo de tumbas romano-imperiales las cuales han sido datadas entre los siglos I-II d. C. ${ }^{15}$. Este enterramien-

15 La tumba ha sido datada en el siglo I d. C. (Blanco, 1998: 7I). to, que se encuentra depositado sobre la cubierta de la tumba ${ }^{\circ}{ }^{15}$, presenta signos de haber sido saqueado pues tan solo se conserva su parte inferior, no habiéndose encontrado restos de ajuar asociados (Blanco, 1998: 7I).

La pesa de cerámica recortada (figura I4, 4), por su parte, procede de la UE $55 \mathrm{I}$ que, junto con la UE $55^{2}$, constituye el enterramiento $\mathrm{n}^{\circ} 67$, incluido dentro del grupo de tumbas de época tardopúnica y romano republicana (siglos III-I a. C.). Se trata de una inhumación en fosa simple con cubierta de sillarejos de piedra ostionera cuya fosa se encuentra excavada en la arcilla natural amarillenta con una orientación noroeste-sureste. La persona allí enterrada se corresponde con un individuo infantil colocado decúbito supino con el cráneo ligeramente vuelto hacia la izquierda, las manos sobre la pelvis, los brazos flexionados y las piernas estiradas. Como ajuar funerario apareció un ungüentario fusiforme de cuello y pie largos depositado sobre el hombro derecho (Blanco, 1998: 53).

Teniendo en cuenta que ninguna de estas pesas parecen formar parte de los ajuares funerarios, es posible que procedan o bien de niveles de relleno de las estructuras funerarias correspondientes o bien de unidades estratigráficas relacionadas con la fase de expolio de la necrópolis. De hecho, sabemos que algunas tumbas fueron saqueadas en época romana imperial tal y como se deduce de la existencia de butrones así como del levantamiento de los sillares. Otra de las posibilidades que tampoco descartamos es que se traten de elementos intrusivos procedentes de la construcción - datada a finales del siglo II a. C. o principios del siglo II a. C.- o remodelación -desde finales del siglo i a. C. hasta mediados del siglo i d. C.- de la factoría de salazones y que habrían podido afectar a estos enterramientos.

Mayor interés presenta una posible punta de arpón (figura 14,5 ) aparecida en la tumba $n^{\circ} 54$ (cuadro D9, UUEE $463 / 465$ ), de época tardopúnica/romano republicana (siglos III-I a. C.). Nos encontramos ante una inhumación en fosa simple con una cubierta a base de un gran sillar regular de piedra ostionera, al que le falta la mitad inferior debido a actividades de expolio. La fosa se encuentra realizada en la arcilla rojiza hasta alcanzar la marga 

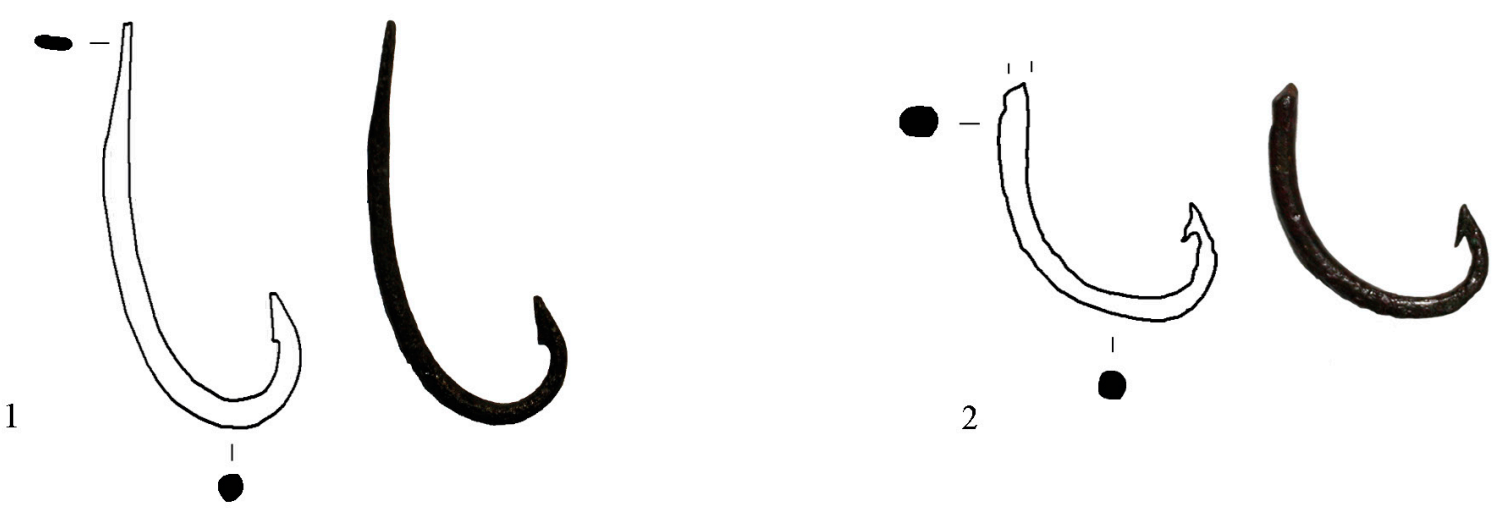

2

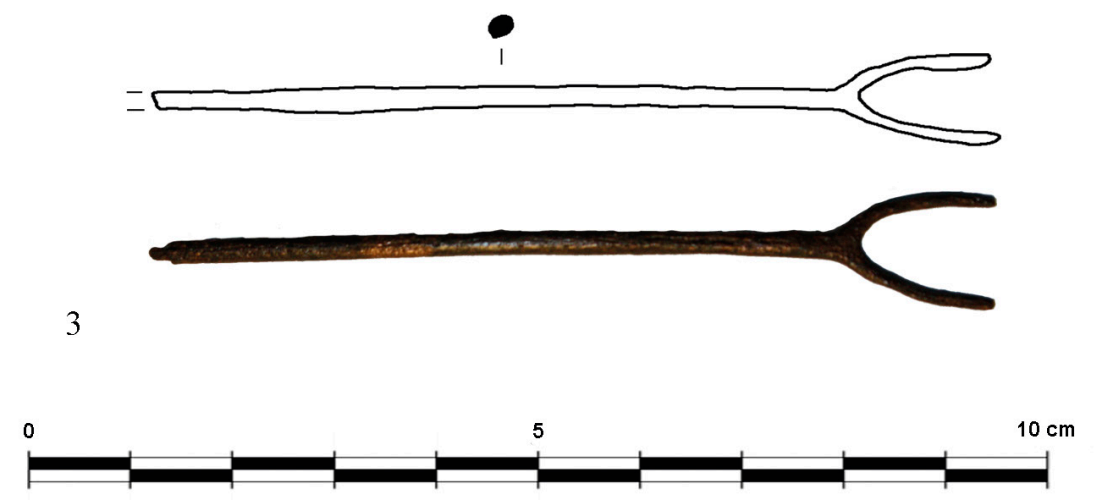

Figura 16. Instrumental pesquero de plaza San Antonio ( $n^{\circ s} 1$ y 2 : anzuelos; $n^{\circ} 3$ : lanzadera)

Figure 16. Fishing instruments from plaza San Antonio (nos. 1 and 2: fishhooks; no. 3: shuttle)

y presenta una orientación noroeste-sureste. $\mathrm{El}$ inhumado es un individuo adulto colocado en posición decúbito supino del que apenas han quedado restos óseos. Esta punta de arpón constituye el único elemento de ajuar documentado en la tumba, situado en la parte inferior de la fosa. Los excavadores, sin embargo, han interpretado este hallazgo como una punta de flecha de bronce (Blanco, 1998: 49).

\subsection{Plaza San Antonio}

Una de las actividades arqueológicas de urgencia más importante realizada en el casco urbano de Cádiz tuvo lugar entre los años I988 y I989 en la plaza San Antonio (figura I, I7), donde aparecieron testimonios de actividades de cantería así como un espacio ocupado por un conjunto estructural de posible carácter industrial tras cuyo abandono se construyó una necrópolis datada entre mediados del siglo I d. C. y principios del siglo III d. C. (una síntesis acerca de la problemática arqueológica de este yacimiento la tenemos en Expósito, 2007: 99-106; y más recientemente en Lara, 2019: ficha de intervención 04). El número total de enterramientos registrados ha sido de 26, I7 de los cuales corresponden a tumbas de incineración y nueve a inhumaciones, identificándose un gran número de individuos infantiles (Expósito, 2007: 104).

De las excavaciones llevadas a cabo en este solar en el año I988 se han recuperado un total de 38 instrumentos de pesca, tres de los cuales podrían proceder de contextos funerarios. Es el caso del anzuelo $\mathrm{n}^{\circ}$ I de la figura $\mathrm{I} 6$, que fue encontrado en el nivel 2 del cuadro A-3, tratándose de un estrato de arena de color castaño de compactación media donde aparecieron materiales cerámicos. A pesar de que no se ha podido determinar la cronología de este contexto, sabemos que se recuperaron sigillatas, ánforas, cerámicas comunes y monedas. Por otra parte, en una ampliación del cuadro A-3 se continuó excavando el nivel 2, documentándose fragmentos de terra sigillata, cerámica de barniz negro campaniense, ánforas, 


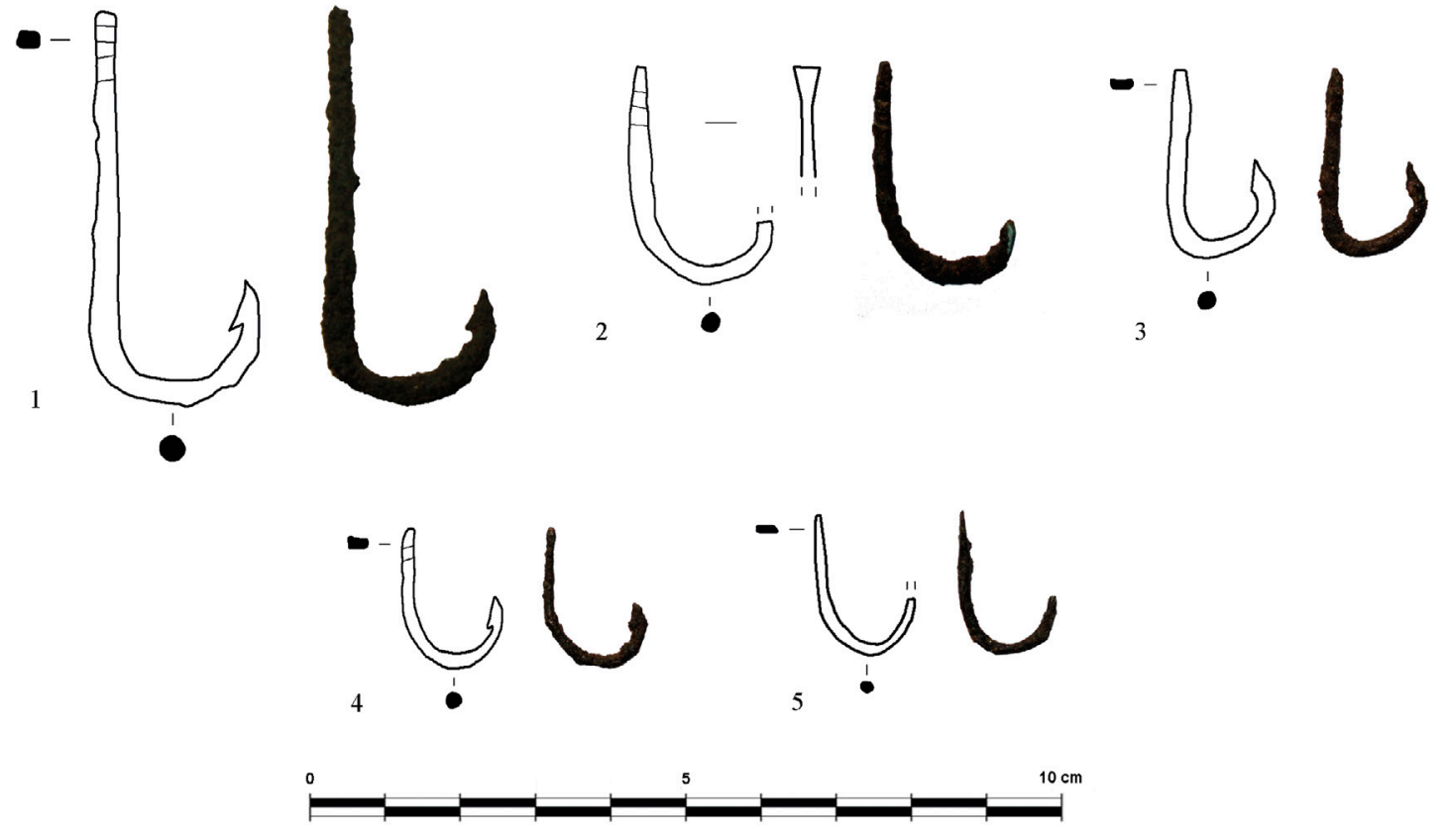

Figura 17. Anzuelos procedentes de contextos funerarios documentados durante las excavaciones de Pelayo Quintero en Puerta de Tierra en 1927

Figure 17. Fishhooks from funerary contexts documented during the excavations of Pelayo Quintero in Puerta de Tierra in 1927

cerámicas comunes, vidrios, clavos y metales ${ }^{16}$. En este mismo cuadro (A-3), el nivel 3 corresponde a una incineración (tumba I) por lo que no descartamos que el nivel 2 constituya una fase de amortización en este sector de la necrópolis ${ }^{17}$.

Por su parte, el anzuelo $\mathrm{n}^{\circ} 2$ de la figura $\mathrm{I} 6$ presenta un contexto arqueológico más dudoso aún si cabe. Sabemos que su hallazgo tuvo lugar en el nivel 6 del cuadro G-2 cuyos datos en el diario de excavación de la campaña de 1988 son escasos e imprecisos. A tenor de la documentación que hemos consultado, se pueden establecer dos posibilidades: o bien que el nivel 6 se corresponda con una tumba de incineración (tumba II) o bien que se trate de un nivel de suelo ${ }^{18}$.

La tercera y última pieza se trata de una lanzadera de bronce (figura 16,3 ) cuyo hallazgo tuvo lugar en el cuadro $\mathrm{H}-2$, desconociéndose la unidad estratigráfica

16 Estos datos han sido extraídos del diario de excavación de la campaña de I988 depositado en la Consejería de Cultura de Cádiz.

17 De hecho sabemos de la existencia de una fase tardorromana en este yacimiento (Expósito, 2007: 104).

18 Estos datos han sido extraídos del diario de excavación de la campaña de 1988 depositado en la Consejería de Cultura de Cádiz. en la que se localizó. Sin embargo, hemos encontrado en el citado diario de campo algunos datos sobre esta cuadrícula que pueden orientarnos acerca del contexto arqueológico donde se produjo el hallazgo de nuestra pieza: el nivel 4 corresponde a un horizonte funerario donde aparecieron varias tumbas mientras que en el nivel 6 se documentó una inhumación.

\subsection{Puerta de Tierra, 1927}

En el Museo de Cádiz se conservan una serie de anzuelos recuperados en las excavaciones llevadas a cabo por Pelayo Quintero en Puerta de Tierra durante el año 1927. En total se han inventariado seis anzuelos (figura I7, I-5) de los cuales la única referencia que tenemos la hemos obtenido de las fichas de inventario de los materiales (Museo de Cádiz, $\mathrm{n}^{\text {os }}$ de inv. 5206, 5208-52II), donde se especifica su procedencia expresa: «necrópolis íbero-romana». En relación a las excavaciones realizadas por Pelayo Quintero en 1927 en la zona extramuros de la ciudad de Cádiz, no hemos obtenido ningún tipo de información, por lo que los datos que hemos podido extraer acerca del contexto arqueológico del instrumental pesquero han sido nulos. 


\section{Categorización de los contextos funerarios}

Tal y como hemos tenido ocasión de comprobar en el apartado anterior, uno de los ambientes donde suelen aparecer con bastante frecuencia evidencias de instrumental pesquero en Gadir/Gades son las necrópolis. Atendiendo a los materiales que hemos estudiado en este trabajo, se han podido categorizar en cuatro grandes grupos los contextos funerarios donde han aparecido artefactos de este tipo.

I. Niveles deposicionales.

2. Estructuras relacionadas con el funcionamiento interno de las necrópolis.

3. Tumbas.

4. Ambientes funerarios indeterminados.

\subsection{Niveles deposicionales}

Algunos de los instrumentos de pesca que hemos integrado en este trabajo proceden de niveles deposicionales excavados en determinados sectores de las necrópolis gaditanas. Para este tipo de contextos la información con la que contamos es poco precisa ya que los informes y las memorias de las excavaciones no suelen especificar la naturaleza de este tipo de depósitos. En cualquier caso, dentro de esta categoría incluimos aquellos niveles que no se relacionan directamente con estructuras funerarias si bien aparecen dentro de los límites espaciales de las necrópolis.

Es el caso de los trabajos arqueológicos realizados en la calle Acacias 2I donde aparecieron una serie de anzuelos y agujas repartidos por el primer nivel deposicional de la necrópolis (UUEE 204, 304 y 404; cuadrículas 2, 3 y 4 respectivamente), no habiéndose podido determinar el origen de esta unidad estratigráfica. Más información tenemos, sin embargo, de las excavaciones realizadas en la calle Acacias 23 donde se recuperó una aguja de bronce en la UE 6. Sabemos que esta unidad estratigráfica constituye un nivel sedimentario de arena dunar y de génesis eólica que sirvió de base para la excavación de las fosas de la gran mayoría de los enterramientos documentados en este solar, pertenecientes a época romana altoimperial. Una situación muy parecida parece advertirse en la calle Santa Cruz de Tenerife r esquina a calle Santa María del Mar de cuyas excavaciones se recuperó un anzuelo de bronce en la UE 2, tratándose de un nivel de duna holocénica sobre el que se excavaron las tumbas tardopúnicas y romanas aparecidas en este solar, habiéndose establecido su período de formación entre los siglos in a. C.-I d. C.

Con los datos que acabamos de exponer, resulta arriesgado determinar cuáles fueron los motivos que provocaron la llegada de instrumental pesquero a estos ambientes funerarios. Sin embargo, podemos plantear algunas hipótesis al respecto. $\mathrm{La}$ razón que parece más evidente es el frecuente trasiego de pescadores en las necrópolis, en la medida en que de su actividad va a depender el abastecimiento de pescado para la celebración de determinados rituales funerarios entre los que se encuentran los propios banquetes así como los sacrificios. En este sentido, se deduce que la figura del pescador tuvo que haber ejercido un importante papel en estas ceremonias ya que los recursos marinos constituyeron la principal fuente de consumo en los banquetes funerarios celebrados en las necrópolis gaditanas. Desde esta perspectiva, la aparición de anzuelos y agujas en estos niveles deposicionales se explicaría por motivos de pérdida ya que el material aparece generalmente disperso - y no concentrado- como resultado de la ida y venida de pescadores en estos ambientes.

Otro de los argumentos que podría explicar la presencia de instrumentos de pesca en estos niveles, está relacionado con el saqueo de las necrópolis, lo cual pudo haber provocado, ya en la Antigüedad, una frecuente dispersión de materiales procedentes del interior de las estructuras funerarias tal y como se puede observar en la Unidad Matriz III ( $\mathrm{a}$ y b) de los Cuarteles de Varela (avenida Andalucía, s/n) donde aparecieron anzuelos, agujas y pesas de red. Este planteamiento no deja de ser tan interesante como el anterior ya que, en este caso, pondría en evidencia el depósito intencionado de instrumental pesquero en el interior de las tumbas como elementos de ajuar. 


\subsection{Estructuras relacionadas con el funcionamiento interno de las necrópolis: zanjas, fosas y pozos}

Las excavaciones arqueológicas realizadas en una serie de solares gaditanos han permitido avanzar en el estado del conocimiento de la estructuración interna de las necrópolis. En este sentido, es muy frecuente que junto a los enterramientos se documenten estructuras negativas que pudieron estar relacionadas tanto espacial como funcionalmente con las propias tumbas y con la liturgia funeraria que rodeaba a estos ambientes (Niveau de Villedary, 2007a: 4I9): zanjas, fosas y pozos.

Por lo que respecta a las zanjas, sabemos que en los trabajos arqueológicos llevados a cabo en la calle Acacias 2I se documentó una zanja en cuyo relleno interior (UE $5 \mathrm{IO}$ ) apareció un anzuelo de bronce. La información con la que contamos es insuficiente si bien la proximidad de esta zanja a una tumba de incineración en cista (E-Ior) ha sido un dato relevante en términos de funcionalidad, pudiéndose tratar de una estructura negativa en cuyo interior se habrían amortizado los restos procedentes de la celebración de ciertos rituales.

Más información tenemos, sin embargo, de las fosas cuya controvertida funcionalidad -en el caso de Gadir/Gades - ha generado un debate historiográfico muy dilatado en el tiempo, habiéndose escrito ríos de tinta para defender tanto la interpretación «funeraria» (Niveau de Villedary, 2007b, 2009, 2010; Niveau de Villedary y Ferrer, 2005) como el carácter «industrial» (Muñoz y de Frutos, 2009) de estas estructuras negativas. Por lo que a los instrumentos de pesca se refiere, sabemos que son elementos de cultura material habituales en los niveles de relleno que colmatan las fosas aparecidas en estos ambientes funerarios. Uno de los ejemplos más representativos lo tenemos en el yacimiento descubierto durante las excavaciones de los antiguos Cuarteles de Varela (calle Marqués de la Ensenada y avenida de la Constitución I8I2) donde se han excavado una serie de estructuras negativas con instrumental pesquero en su interior. Es el caso de la Fosa I, amortizada por un nivel de relleno a modo de vertido (UE Io) donde se documentaron varios utensilios de pesca (dos anzuelos y una aguja de bronce) entre el abundante material arqueológico recuperado, principalmente de tipo cerámico. La misma situación parece advertirse en la Fosa 3 en cuyos niveles de colmatación ( $\mathrm{UE}_{5 \mathrm{I}}$ ) también aparecieron instrumentos de pesca (una aguja de bronce) mezclados con las diferentes acumulaciones de vertidos de restos materiales cerámicos y alimenticios.

No menos interés tienen las tres fosas excavadas en la arcilla descubiertas en el solar del Palacio de la Justicia. Si bien el número de instrumental pesquero aparecido es mucho más numeroso y variado que en el caso anterior (23 piezas: anzuelos de bronce, pesas de plomo, un cuchillo de hierro y agujas metálicas), la información arqueológica de la que disponemos actualmente no nos ha permitido precisar el contexto crono-estratigráfico de los materiales. Sea como fuere, sabemos que los utensilios de pesca constituyeron elementos habituales en los niveles de colmatación de estas fosas, mezclándose con otros materiales de diferente naturaleza.

Tanto en el caso de los Cuarteles de Varela (fosas $n^{\text {os }}$ I y 3 ) como en el del Palacio de la Justicia (fosas $\mathrm{n}^{\mathrm{os}}$ I, 2 y 3 ) la presencia de instrumental pesquero sería un indicio más para verificar el importante papel que desempeñaron las artes y aparejos de pesca en estos ambientes funerarios. Desde esta perspectiva, su aparición en el interior de estas fosas supondría que los artefactos de pesca fueron amortizados junto con los restos de vajilla y alimentos procedentes de los banquetes funerarios celebrados alrededor de las tumbas, cumpliendo, de este modo, una función doble: utilitaria, en primer lugar, siendo su último uso de carácter, posiblemente, votivo.

Junto a las zanjas y a las fosas, otro tipo de estructuras negativas - esta vez constructivas- muy frecuentes en las necrópolis gaditanas son los pozos. Al igual que las fosas, la funcionalidad de los pozos no ha estado exenta de polémica (Niveau, 20orb), existiendo diferentes opiniones a la hora de atribuir un carácter «funerario» $y / 0$ «industrial» a estas construcciones. En las excavaciones realizadas en la Tesorería General de la Seguridad Social (avenida Amílcar Barca) apareció una aguja de bronce en el interior de uno de los tres pozos documentados en este solar (pozo n ${ }^{\circ} 2$ ). $\mathrm{La}$ composición de los dos niveles de relleno excavados en su interior induce a pensar que este pozo se haya utilizado, al menos en su último momento, para verter la 
«basura» procedente de las limpiezas cíclicas acontecidas en la necrópolis (Arévalo, 20II-20I2: 527), de ahí la abundante frecuencia de lápidas funerarias y restos de cenizas procedentes posiblemente de incineraciones.Por todo lo que llevamos dicho, la presencia de una aguja de red en el interior de este pozo se explicaría por el mismo proceso post-deposicional que el resto de los materiales aparecidos, pudiendo haber pertenecido, en su contexto original, al ajuar funerario de alguna tumba.

\subsection{Tumbas}

La gran mayoría de los instrumentos de pesca presentados en este trabajo proceden de tumbas, siendo muy variadas las razones que explicarían la presencia de este tipo de útiles en estos contextos funerarios.

En primer lugar, sabemos de la aparición de instrumental pesquero en el interior de las fosas de construcción de las tumbas. Es el caso de uno de los enterramientos documentado en las excavaciones realizadas en la calle García Carrera 9 (tumba no 63). En este solar se excavó una tumba de incineración en doble urna (vidrio y plomo) depositada en el interior de una estructura de planta cuadrangular (UUEE 374-378) para cuya construcción se abrió una fosa (UE 354) donde apareció un anzuelo de bronce. De la misma manera, en las excavaciones llevadas a cabo en la calle San Juan Bautista esquina a calle Marqués de Coprani apareció una pesa de red de cerámica en el nivel de relleno (UE ${ }_{52}$ ) que colmataba el interior de una fosa abierta para la construcción de una tumba de incineración de tipo bustum (UE ro: Estructura Funeraria 2). En este último caso, sabemos que la pieza apareció asociada a otros elementos de cultura material tales como fragmentos cerámicos (siglo I d. C.) y objetos metálicos como pueden ser botones y monedas. Para el caso de las monedas, se ha planteado que su presencia en este nivel de relleno se debe a un acto de sacralización de la inauguración de la fosa de construcción de la propia tumba (Arévalo y Moreno, 2017: 5-7) aunque esta interpretación es difícilmente extrapolable al resto de materiales ya que tenemos que tener en cuenta que la estructura funeraria fue saqueada ya en la Antigüedad. En este sentido, la escasez de datos con los que contamos actualmente no nos permite determinar si la pesa de red fue depositada intencionalmente o si por el contrario su aparición en la fosa de construcción de la tumba se debe a procesos post-deposicionales. Sea como fuere, el hallazgo de esta pieza en este contexto y su asociación a una serie de monedas de Gadir no deja de ser un dato relevante a la hora de plantear el posible carácter votivo de este lastre cerámico, al menos en su último momento de uso.

En segundo lugar, contamos con una serie de instrumentos de pesca cuya aparición en el interior de sepulturas podría explicarse gracias a procesos post-deposicionales, tal y como han demostrado algunos de los ejemplares recuperados en las excavaciones realizadas en la plaza Asdrúbal de Cádiz durante la década de los años 80 y 90 del pasado siglo. Nos estamos refiriendo, en primer lugar, a los controvertidos hallazgos descubiertos en las tumbas 6 y 7 de la denominada zona $\mathrm{F}$, ambas excavadas durante la campaña de 1985 , donde la presencia de utensilios de pesca respondería a diferentes causas. En el caso de la tumba 6, la apertura de su fosa de construcción sobre el nivel púnico de uso industrial de la zona ha permitido plantear que tanto los artefactos como los ecofactos asociados a este enterramiento se encontraban en posición secundaria, debiéndose relacionar con la rotura de los depósitos pesqueros-conserveros preexistentes (Bernal-Casasola et alii, 2014: 217). Por lo que respecta a la tumba 7 , sabemos que su cabecera se vio afectada por una de las fosas de carácter haliéutico documentadas en la zona F de este yacimiento, cuya funcionalidad fue la de servir de receptáculo para arrojar los desechos procedentes de la incesante industria pesquero-conservera púnico-gaditana de este sector, integrándose en estos depósitos restos de ictiofauna, malacofauna, cerámicas y evidencias de instrumental pesquero como las que traemos a colación $(\text { Bernal-Casasola et alii, 20I4: 223 })^{19}$.

\footnotetext{
19 En este mismo solar, si bien en la denominada zona E, aparecieron dos agujas de bronce en una inhumación en fosa simple (tumba 2) que no parece haber sido afectada por ninguna de las fosas haliéuticas relacionadas con los saladeros púnicos. Sin embargo, no descartamos que la aparición de utensilios de pesca en esta tumba se deba al mismo proceso post-deposicional que hemos advertido en el caso de la tumba 6 .
} 
De este modo, los anzuelos de bronce documentados en el interior de estas estructuras funerarias podrían constituir elementos intrusivos como consecuencia del doble uso - industrial/funerario- que tuvo este sector de Gadir en época púnica.

Una situación similar a la anteriormente descrita podría haberse producido en una de las tumbas excavadas durante los trabajos arqueológicos realizados en un solar próximo al anterior (plaza Asdrúbal, 1997-1998). Nos referimos a una de las tumbas pertenecientes a la fase tardopúnica/romano republicana del yacimiento — siglos III-I a. C.(tumba 6I), donde aparecieron varias pesas de cerámica discoidales en el interior de una «fosa negra» cuya interpretación más plausible es que se trate de una fosa haliéutica donde se habrían arrojado elementos relacionados con la actividad pesquero-conservera.

Sin embargo, existen otras razones para explicar el carácter post-deposicional de la presencia de utensilios de pesca en el interior de los enterramientos, como puede ser el saqueo. Uno de los ejemplos más representativos en este sentido lo encontramos en una de las tumbas romanas altoimperiales (siglos I-II d. C.) aparecidas durante las excavaciones arqueológicas llevadas a cabo en la plaza Asdrúbal (campañas comprendidas entre 1997 y 1998). En efecto, la tumba I4 presentó evidentes signos de saqueo de lo que se deduce que solo se haya conservado su parte inferior así como que no hayan aparecido evidencias de ajuar. Desde esta perspectiva, la aparición de varias pesas de cerámica de tipo discoidal en el interior de esta sepultura podría ser una consecuencia directa de la rotura de niveles industriales, practicándose una o varias fosas de expolio donde habrían quedado enterrados elementos de cultura material procedentes de los depósitos suprayacentes. Otra de las razones que tampoco descartamos es la participación de pescadores en estas actividades de saqueo, produciéndose pérdidas ocasionales de sus instrumentos de pesca en los enterramientos expoliados.

Por otra parte, contamos con una serie de instrumentos de pesca de los cuales se desconocen las causas que propiciaron su aparición en el interior de estructuras funerarias. Es el caso de algunos de los hallazgos descubiertos en la necrópolis excavada en la calle Acacias 2I donde sabemos que en las estructuras 3I, 29 y III aparecieron utensilios pesqueros (un anzuelo, dos agujas y una aguja respectivamente), no habiéndose podido determinar si los materiales aparecieron en posición primaria - como ajuar funerario por ejemplo- o si por el contrario su presencia en estos receptáculos se debe a procesos post-deposicionales. En esta misma línea se sitúan las dos agujas de bronce recuperadas en el interior de una estructura cuadrangular, a modo de recinto funerario, excavada en la calle Brunete 2, si bien en este último caso sabemos que la construcción fue parcialmente destruida por saqueo.

Por lo que respecta al hallazgo de instrumenta piscatoria en el interior de tumbas, las excavaciones en las necrópolis de Gadir/Gades han permitido corroborar que los utensilios de pesca constituyen un elemento habitual entre las ofrendas que conforman los ajuares funerarios de los difuntos. En total han sido II los enterramientos donde hemos documentado artefactos pesqueros cuya deposición parece responder a un acto de carácter ritual, observándose una presencia indiscriminada de este tipo de materiales tanto en tumbas de incineración (seis casos) como de inhumación (cinco ejemplos).

En relación a las tumbas de incineración, la gran mayoría de los instrumentos de pesca documentados aparecieron en fosas simples (cuatro ejemplos). Es el caso de la aguja de hueso procedente de una tumba de incineración en fosa simple primaria (T-I79) excavada en los solares de la avenida Andalucía 2I-27 y calle General Ricardos 2. La pieza apareció quemada por lo que intuimos que los elementos de ajuar o bien habrían sido incinerados junto al cuerpo del difunto, o bien habrían estado situados en las proximidades de la fosa durante la incineración. Un hallazgo similar tuvo lugar en la tumba 44 descubierta durante las excavaciones en la calle Tolosa Latour (1987), que constituye una tumba de incineración en fosa simple de época romana excavada en la arena parda o arcilla (nivel 2-3) sin ningún tipo de protección. En este enterramiento apareció una aguja de hueso que, a diferencia del ejemplo anterior, no presentaba signos de haber sido incinerada, por lo que intuimos que su deposición tuvo lugar con posterioridad a la incineración del difunto. Mayor información 
tenemos de los dos anzuelos de bronce aparecidos en una tumba de incineración en fosa simple (tumba 2) durante las excavaciones en la calle Acacias 23. En este caso, sabemos que el instrumental pesquero aparece acompañado de otros elementos de ajuar ya que, junto a los restos óseos quemados, aparecieron numerosos fragmentos de hierro - pertenecientes posiblemente a la parihuela donde se solían transportar a los difuntos- así como un ungüentario de vidrio piriforme, dos monedas de bronce y un cuenco lucerna de cerámica común fragmentado. Otro hallazgo de gran interés lo tenemos constatado en una de las tumbas descubiertas durante las excavaciones realizadas en la calle Santa Cruz de Tenerife I esquina a la calle Santa María del Mar. Nos estamos refiriendo a la aguja descubierta en la «E.F. 34", que constituye una incineración en fosa simple de tipo bustum sin ningún tipo de protección, fechada en el siglo I d. C. En este caso, al igual que vimos en el ejemplo anterior, la aguja broncínea aparece acompañada de otros elementos de ajuar tales como un borde de cuenco de cerámica romana, un borde de jarrita, un clavo y una pequeña lámina de bronce. Por último, contamos con la aparición de una aguja de bronce en una tumba de incineración $\left(n^{\circ} 3\right)$ descubierta durante las excavaciones llevadas a cabo en la calle Acacias 25, de la cual no hemos podido obtener ningún tipo de información. Menos frecuentes son, sin embargo, los hallazgos de instrumentos de pesca en el interior de urnas funerarias. De todos los materiales que hemos inventariado tan solo uno de ellos podría proceder de una tumba de incineración en urna de cerámica. Es el caso de la aguja de bronce aparecida en la tumba T-r37, documentada en los solares correspondientes a la avenida Andalucía 2I-27 y calle General Ricardos 2, desconociéndose si aparecieron otros elementos de ajuar asociados.

En lo que se refiere a las tumbas de inhumación, lo más frecuente es que los instrumentos de pesca aparezcan formando parte de los ajuares funerarios en fosas simples. Es el caso de la aguja de bronce aparecida en la tumba 4 (UUEE ${ }_{52} / 54$, siglo ir a. C.) excavada durante las excavaciones realizadas en los Cuarteles de Varela (calle Marqués de la Ensenada y avenida de la Constitución I8I2, Fase II, año 2000). La mencionada tumba — que había sido expoliada - se trataba de una inhumación en fosa simple excavada en la arcilla rojiza en cuya cabecera apareció una aguja broncínea, no habiéndose podido determinar si esta pieza apareció asociada a otros elementos de ajuar. Otro ejemplo de especial interés es el hallazgo de una punta de arpón en una de las tumbas documentadas en plaza Asdrúbal (1997-1998). Nos estamos refiriendo a una inhumación en fosa simple con una cubierta conformada por un gran sillar regular de piedra ostionera con signos de expolio, ya que su mitad inferior se había perdido. Otra fosa simple donde sabemos que apareció instrumental pesquero corresponde a la tumba 7 excavada en la calle Acacias 23, localizándose, a la altura de la cadera, un molusco bajo el cual se halló un anzuelo de bronce a lo que tenemos que sumar un otolito de corvina a la altura del pecho y otros elementos de ajuar de tipo cerámico. Junto a los hallazgos en fosas simples que acabamos de describir, en el sector de necrópolis excavado en la avenida Portugal esquina a avenida Andalucía apareció un anzuelo de bronce en una posible tumba de inhumación en cista de sillares regulares de piedra ostionera (tumba/enterramiento I8). La tumba, que había sido expoliada tal y como se deduce de la aparición de restos óseos entre varios sillares movidos, integraba otros elementos de ajuar de tipo cerámico junto con el anzuelo broncíneo que traemos a colación. Por último, mencionar la aparición de una aguja de bronce formando parte del ajuar funerario de una de las inhumaciones infantiles ( $\mathrm{LP} / 25)$ documentadas en la avenida López Pinto (I980).

\subsection{Ambientes funerarios indeterminados}

Finalmente, dentro de esta categoría incluimos una serie de hallazgos de instrumental pesquero cuyo contexto arqueológico no hemos podido precisar. Nos estamos refiriendo, en primer lugar, a los materiales procedentes de las antiguas excavaciones 1levadas a cabo entre I916 y I9I7 por Pelayo Quintero en la zona de Baños del Blanco, donde aparecieron dos anzuelos, seis agujas de bronce y una lanzadera. En segundo lugar, contamos con una serie de anzuelos aparecidos durante las excavaciones de Pelayo Quintero en el año I927 en la necrópolis de Puerta 
Tierra. Tanto en un caso como en otro, desconocemos los contextos arqueológicos donde se produjeron los hallazgos de cada una de estas piezas, no habiéndose podido precisar si aparecieron en el interior de estructuras funerarias o al exterior de ellas.

\section{Valoración general}

A lo largo de este trabajo se ha podido comprobar cuan problemático resulta el estudio de las necrópolis de Gadir/Gades, siendo varios los motivos de esta situación. El problema que resulta más evidente es aquel que deriva de la propia información contenida en los informes y las memorias de las intervenciones arqueológicas, cuyos datos son, en la gran mayoría de los casos, insuficientes e imprecisos, provocando que resulte muy complejo conocer con claridad la interpretación de las unidades estratigráficas y constructivas. En segundo lugar, la superposición de tumbas de diferentes momentos históricos (las romanas sobre las de época fenicio-púnica) genera confusión a la hora de determinar la atribución crono-cultural de los contextos arqueológicos, ya que la rotura de una estructura funeraria para la construcción de una nueva provocaría la mezcolanza de materiales de diferentes períodos, por lo que muchos de ellos no se encontrarían en su posición original. A todo ello tenemos que sumarle las incesantes actividades de expolio llevadas a cabo durante la Antigüedad, de cuya práctica tenemos interesantes evidencias arqueológicas en las necrópolis gaditanas. La frecuente aparición de instrumentos de pesca en tumbas que presentan signos evidentes de haber sufrido expolio es un dato relevante a la hora de valorar la posible participación de pescadores en estas hazañas, máxime si tenemos en cuenta la proximidad de las necrópolis a las fábricas salazoneras.

Los instrumentos de pesca suelen ser elementos de cultura material muy habituales en los ambientes funerarios de las necrópolis antiguas. La costumbre de depositar intencionalmente artes y aparejos de pesca en el interior de tumbas se remonta al Pleistoceno, tal y como ha puesto de manifiesto recientemente el hallazgo de cinco anzuelos y un bivalvo perforado en un enterramiento femenino documentado en la isla de Alor, en Indonesia (O'Connor et alii, 20I7). Estos anzuelos son los ejemplares más antiguos que se conocen asociados a prácticas funerarias a nivel mundial, con una datación de entre I2000 y IIooo años, denotando el carácter cosmológico de la pesca en las poblaciones insulares de Indonesia así como la importancia de los artefactos pesqueros en el viaje de ultratumba de los difuntos (O'Connor et alii, 20I7: I452 y I466).

A escala atlántica-mediterránea, se conocen enseres de pesca formando parte de ajuares funerarios desde, al menos, la Edad del Bronce, tal y como demuestran los hallazgos aparecidos en una tumba de cámara ( $\mathrm{n}^{\circ}$ I3I) de Perati, asentamiento costero del Ática, pertenecientes al Heládico Reciente III C (siglo XII a. C.). En el interior de esta estructura funeraria aparecieron una serie de pesas laminares de plomo (I2 ejemplares), pertenecientes a una misma red, asociadas a un anzuelo de bronce. Este lote de instrumental pesquero aparecía acompañando, a modo de ajuar, al difunto allí enterrado, que podría haber sido pescador $\mathrm{y}$, por ende, propietario de los aparejos con los que fue enterrado (AA.VV., I992: 299).

En el caso de Gadir/Gades la presencia (intencionada o no) de artefactos de pesca en contextos funerarios se tiene constatada desde época púnica (siglo iv a. C.) aunque es posible que los orígenes de este fenómeno deban remontarse a finales del siglo vi a. C., momento en el que se constatan las evidencias pesquero-conserveras más antiguas en esta ciudad. La aparición de hallazgos de este tipo en las necrópolis gaditanas se tiene documentado sobre todo en época tardopúnica/romano republicana y época romana altoimperial (siglos III a. C.-II d. C.), coincidiendo con el período de actividad de la factoría de salazón descubierta en la plaza Asdrúbal de Cádiz (campañas de 1997-I998), cuya cronología se ha establecido entre finales del siglo III a. C. o principios del siglo II a. C. hasta mediados del siglo I d. C., y en cuyos alrededores han aparecido la gran mayoría de los instrumentos de pesca presentados en este trabajo. Por otra parte, se desconocen materiales pesqueros en la necrópolis tardorromana gaditana debido posiblemente al cese de las producciones piscícolas en el conjunto industrial anteriormente mencionado. 
En otras ciudades, como por ejemplo el territorio onubense, tenemos noticias de la aparición de anzuelos simples en tumbas bajoimperiales. Estos hallazgos constituyen un testimonio de vital interés pues vienen a demostrar que la costumbre de depositar anzuelos en el interior de tumbas como elementos de ajuar perdura hasta época tardía. Nos referimos a la necrópolis de El Eucaliptal (Punta Umbría, Huelva) cuya excavación tuvo lugar en el año I994 por parte del Área de Arqueología de la Universidad de Huelva en el marco de una intervención de urgencia. Esta necrópolis se ha puesto en relación con la factoría de salazones de nombre homónimo, de ahí que se haya definido como una necrópolis de pescadores (Campos et alii, 1999). En el enterramiento $\mathrm{n}^{\circ} \mathrm{I}$ (UE 9 ) apareció una inhumación en posición decúbito supino que portaba en su mano derecha un anzuelo. Al parecer los restos del inhumado pertenecían a un hombre de entre 30 y 40 años de edad que presentaba como patología más destacada una fractura en el antebrazo izquierdo (Campos et alii, 1999: 199). Sabemos que se trata de una inhumación en tumba de ladrillos perteneciente a la fase III de la necrópolis cuya datación se ha establecido a principios del siglo $\mathrm{v} d$. C.

Otra necrópolis del área de influencia onubense donde han aparecido instrumentos de pesca formando parte de los ajuares de los difuntos es la documentada en La Viña (Isla Cristina), en cuyas tumbas tardías (fase I: finales del siglo II-mediados del siglo iII d. C.; fase II: mediados del siglo III-finales del siglo Iv) se recuperaron anzuelos de bronce y de hierro, agujas de coser, plomadas y cuchillos para el corte y procesado del pescado (Fernández Sutilo, 20r6).

E1 hallazgo de instrumental pesquero en el interior de tumbas formando parte del ajuar funerario de los difuntos se ha convertido en un testimonio de vital interés para la reconstrucción de aspectos sociales tales como el trabajo u oficio de la persona allí enterrada. En este sentido, es posible que los restos humanos documentados en algunas tumbas gaditanas pertenecieran a pescadores, los cuales fueron enterrados con los enseres que formaron parte de su día a día y que, por ende, más apreciaron en vida. De esta manera, sus seres queridos consiguen, de una manera simbólica, hacerle más afable su viaje al «más allá». Por otro lado, más allá del carácter votivo de estos enseres, otra de las hipótesis que tampoco debemos descartar es la atribución de significado ritual e incluso apotropaico a determinados instrumentos de pesca, adquiriendo, en este caso, un cariz mágico-religioso equiparable al valor que presentan otros amuletos frecuentemente depositados en el interior de estructuras funerarias.

Por lo general, los instrumentos de pesca suelen aparecer acompañados de otros elementos de ajuar a excepción de la tumba no 54 de la plaza Asdrúbal (1997-I998) en la que se documentó una punta de arpón de manera exclusiva. Normalmente aparecen materiales cerámicos, siendo frecuente el hallazgo de ungüentarios (destacando aquellos de forma piriforme típicamente helenísticos así como los modelos fusiformes), fragmentos anfóricos y de cerámica común romana (ollas, cuencos, jarritas, cuencos lucernas, entre otros). Menos habituales son, sin embargo, los elementos de vidrio y las monedas, habiéndose documentado un único enterramiento (tumba $\mathrm{n}^{\circ} 2$ de la calle Acacias 23) donde aparece instrumental pesquero (dos anzuelos en este caso) asociado a material vítreo (un ungüentario piriforme) y a numerario de bronce (dos ejemplares). Por otro lado, es frecuente la aparición de fragmentos de hierro que en la gran mayoría de los casos corresponden a clavos pertenecientes a ataúdes o parihuelas. De gran interés ha sido la tumba 7 descubierta en el solar de la calle Acacias 23 donde apareció un anzuelo de bronce asociado a una valva de molusco a lo que tenemos que sumar el hallazgo de un otolito de corvina. De todo ello se deduce que son ajuares pobres lo que unido a la simplicidad de las tumbas (inhumaciones e incineraciones en fosas simples en la gran mayoría de los casos) induce a pensar en el bajo rango social de las personas allí enterradas.

A tenor de los datos que hemos expuesto en este trabajo, los instrumentos de pesca que suelen aparecer con mayor frecuencia en los ajuares funerarios de las tumbas gaditanas son los anzuelos de bronce así como las agujas de metal y, en menor medida, de hueso. De carácter excepcional ha sido el hallazgo de una punta de arpón en un enterramiento de época tardopúnica/romano republicana, cuya escasa representación en el registro funerario gaditano puede deberse 
a que este tipo de artefactos arrojadizos fueron poco frecuentes en las actividades de pesca de Gadir/Gades pues el ejemplar que traemos a colación, descubierto en la tumba $n^{\circ} 54$ de plaza Asdrúbal (campañas de 1997-I998), es el único que se conoce en nuestra ciudad. Son totalmente inexistentes, por su parte, las evidencias de redes en los ajuares funerarios, desconociéndose la aparición de restos físicos de estas artes en las necrópolis gaditanas como sí ocurre, por ejemplo, en la necrópolis ibérica de La Albufereta en cuya sepultura L-I7 (conocida tradicionalmente como «tumba del pescador») apareció un pequeño fragmento de red asociado a otros elementos de ajuar. Tampoco se conocen hallazgos de lastres pesqueros formando parte de los ajuares funerarios, todo lo cual invita a pensar que las artes de redes no solían acompañar a los pescadores gaditanos en su viaje de ultratumba,

\section{Bibliografía}

AA.VV. (1992): El mundo micénico. Cinco siglos de la primera civilización europea (I60о-IIоo a. C.). Ministerio de Cultura. Madrid.

Arévalo, A. (20II-20I2): "Continuidad e impronta púnica en la necrópolis de Gades. Evidencias monetales". Cuadernos de Prehistoria y Arqueología de la Universidad Autónoma de Madrid, 37-38: 525-538.

Arévalo, A. y Bernal-Casasola, D. (2004): "Agujas de red”. En A. Arévalo, D. Bernal-Casasola y A. Torremocha (eds.): Garum y salazones en el Circulo del Estrecho. Catálogo de la Exposición. Ediciones Osuna. Granada: II2-II3.

Arévalo, A. y E. Moreno (2016): "La moneda en las necrópolis de Gadir/Gades”. En A. Arévalo (ed.): Monedas para el más allá. Uso y significado de la moneda en las necrópolis tardopúnicas y romanas de Ebusus, Gades y Malaca. Universidad de Cádiz. Cádiz: 75-193.

Arévalo, A. y E. Moreno (20I7): "La presencia de moneda en los diferentes momentos rituales funerarios de Gades a partir de época augustea". Onoba, 5: 3-19. pudiendo ser heredadas por otros familiares dedicados a estas actividades, si bien la parquedad de la información a la que hemos tenido acceso induce a ser cautelosos en este sentido. Tampoco se conocen evidencias de lanzaderas en los ajuares funerarios de las tumbas gaditanas, algo que contrasta con otras necrópolis tanto de época púnica, como es el caso de Puig des Molins (Ibiza, Baleares), como de época romana, tal y como demuestran el hallazgo de varios ejemplares en la necrópolis oriental de Baelo Claudia (Arévalo y Bernal-Casasola, 2004: II2-II3). En este último caso, las lanzaderas fueron recuperadas en el marco de las excavaciones de Pierre Paris a principios del siglo xx, desconociéndose el contexto arqueológico donde se produjeron estos hallazgos, por lo que no podemos afirmar con total seguridad que pertenezcan a elementos de ajuar.

Bejarano, D. (2003): Aparcamiento subterráneo "Antiguos Cuarteles de Varela". avenida Andalucía s/n (Cádiz). Intervención arqueológica de urgencia $(\mathrm{CV}-\mathrm{O} 2)$. Original inédito depositado en la Delegación Provincial de Cádiz, Consejería de Cultura de la Junta de Andalucía.

Bekker-Nielsen, T. (2010): "Fishing in the Roman World". En T. Bekker-Nielsen y D. Bernal-Casasola (eds): Ancient nets and fishing gear: proceedings of the international workshop on 'nets and fishing gear in classical antiquity: a first approach' (Cádiz, 5-I7 Nov. 2007). Universidad de Cádiz y Aarhus University Press. Cádiz y Aarhus: 187-294. Bernal-Casasola, D., Muñoz, A., Marlasca, R., Cantillo, J.J., Vargas, J.M. y Lara, M. (20I4): "Atunes ronqueados y conchas de la plaza de Asdrúbal. Novedades haliéuticas en los saladeros gadiritas”. En J.J. Cantillo, D. Bernal-Casasola y J. Ramos (eds.): Moluscos y púrpura en contextos arqueológicos atlántico-mediterráneos. Nuevos datos y reflexiones en clave de proceso histórico, Actas de la III Reunión Científica de Arqueomalacología de la Peninsula Ibérica (3-4 de diciembre de 2012, Cádiz). Universidad de Cádiz. Cádiz: 205-228. 
Blanco, F.J. (1996): Informe de los resultados obtenidos en la excavación arqueológica del solar número 2 de la calle Brunete. Original inédito depositado en la Delegación Provincial de Cádiz, Consejería de Cultura de la Junta de Andalucía.

Blanco, F.J. (1998): Memoria de las excavaciones efectuadas en el solar ubicado en la Plaza de Asdrúbal esquina con el Paseo Marítimo durante 1997/98. Original inédito depositado en la Delegación Provincial de Cádiz, Consejería de Cultura de la Junta de Andalucía.

Blanco, F.J. (2000): Informe-memoria de las excavaciones arqueológicas efectuadas en las parcelas: 40 V.P.P., locales, garajes y oficinas (Fase 2) (c/Marqués de la Ensenada y avenida de la Constitución I8I2) Cádiz. I8 V.P.O. locales y garajes (c/ Marqués de la Ensenada). UE-EX6 Cuarteles de Varela, Cádiz. Original inédito depositado en la Delegación Provincial de Cádiz, Consejería de Cultura de la Junta de Andalucía.

Blanco, F.J. y P. Bueno (2005): Informe de las excavaciones arqueológicas realizadas en la avenida de Portugal esquina con la avenida Andalucia para la construcción de un hotel. Original inédito depositado en la Delegación Provincial de Cádiz, Consejería de Cultura de la Junta de Andalucía.

Blanes, C. (1999): Inventario de materiales arqueológicos procedentes de la intervención arqueológica en calle Acacias 2I, Cádiz (Acta de depósito de materiales). Original inédito depositado en la Delegación Provincial de Cádiz, Consejería de Cultura de la Junta de Andalucía.

Bueno, P. y I. Legupín (2005): Informe preliminar de la excavación arqueológica preventiva realizada en la c/ Acacias no 25 (Cádiz). Original inédito depositado en la Delegación Provincial de Cádiz, Consejería de Cultura de la Junta de Andalucía.

Campos,J.M., Pérez,J.A.y Vidal, N. de la O (I999): "El Eucaliptal, una necrópolis romana de pescadores (Punta Umbría, Huelva)". Huelva en su Historia, VII: 195-23I.

Carrero, F. (2013): Pesca, consumo y problemática histórico-arqueológica de la corvina, argyrosomus regius, en el mundo antiguo. Trabajo de Investigación de Fin de Máster inédito, Universidad de Cádiz.
Córdoba, I. y R. Belizón (2006): Memoria final Actividad Arqueológica Preventiva Excavación solar c/ García Carrera, 9 (Cádiz). Original inédito depositado en la Delegación Provincial de Cádiz, Consejería de Cultura de la Junta de Andalucía. Córdoba, I. y M.A. Navarro (1999): Informe arqueológico preliminar de urgencia en el solar de la Avenida Andalucia no 2I, 23, 25 y 27 y $n^{\circ} 2$ de la calle General Ricardos (Cádiz). Original inédito depositado en la Delegación Provincial de Cádiz, Consejería de Cultura de la Junta de Andalucía.

Corzo, R. (1989): "Los sacrificios infantiles en Cádiz". Cuadernos de Prehistoria y Arqueología Castellonense, I4: 239-246.

Corzo, R. (1992): “Topografía y ritual en la necrópolis de Cádiz". SPAL, r: 263-292.

Expósito, J.A. (2007): Las factorias de salazón de Gades (siglos II a. C.-VI d. C.). Estudio arqueológico y estado de la cuestión. Universidad de Cádiz. Cádiz.

Fernández Sutilo, L. (2016): Espacio y usos funerarios en Onoba y su área de influencia entre los siglos II a. C.-VII $d$. C. Tesis doctoral inédita. Universidad de Huelva. Huelva.

García Vargas, E. (2016): "Littoral landscapes and embedded economies: tuna fisheries". En T. Bekker-Nielsen y R. Gertwagen (eds.): The inland seas: towards an ecohistory of the Mediterranean and the Black Sea. Franz Steiner Verlag. Stuttgart: 255-286.

Hanson, K.C. (1997): "The Galilean Fishing Economy and the Jesus Tradition”. Biblical Theology Bulletin, 27: 99-III.

Lara, M. (2019): Urbs Iulia gaditana. Arqueología y urbanismo en la ciudad romana de Cádiz al descubierto. Universidad de Cádiz. Cádiz.

López Amador, J.J. y J.A. Ruiz Gil (2010): "Las ofrendas del santuario púnico-gaditano de $\mathrm{La}$ Algaida (Sanlúcar de Barrameda)". En E. Mata (coord.): Cuaternario y Arqueología: Homenaje a Francisco Giles Pacheco. Diputación Provincial de Cádiz. Cádiz: 271-279.

López Amador,J.J y J.A. Ruiz Gil (20I4): "Un amuleto fenopúnico del Golfo de Cádiz”. En A.M. Arruda (ed.): Fenícios e Púnicos, por terra e mar. Actas do VI Congresso Internacional de Estudos Fenícios e Púnicos (25 de Setembro a I de Outubro de 2005, Lisboa), Vol. 2. UNIARQ. Lisboa: 788-799. 
Molina, M.I. (1997a): Intervención arqueológica de un solar en c/ San Juan Bautista esquina a c/ Marqués de Coprani (Los Chinchorros). Cádiz, 1997. Original inédito depositado en la Delegación Provincial de Cádiz, Consejería de Cultura de la Junta de Andalucía.

Molina, M.I. (1997b): Intervención arqueológica en un solar de c/ Sta. Cruz de Tenerife no I E/ c/ Sta. María del Mar. Cádiz, 1997. Original inédito depositado en la Delegación Provincial de Cádiz, Consejería de Cultura de la Junta de Andalucía.

Moya, L. (2016): Tyria Maria. Los fenicios occidentales y la explotación de los recursos marinos. Universidad de Sevilla. Sevilla.

Muñoz, A. (20I2): "Artes y aparejos de pesca fenicio-púnicos en el Mediterráneo Occidental: el ejemplo del Círculo del Estrecho". En B. Costa y J.H. Fernández (eds.): Sal, pesca y salazones fenicios en Occidente. XXVIJornadas de Arqueología Fenicio-Púnica (Eivissa, 20II). Museo Arqueológico de Ibiza y Formentera. Ibiza: 33-84.

Muñoz, A. y De Frutos, G. (2009): "La pesca y las conservas en la Bahía de Cádiz en época fenicio-púnica”. En D. Bernal-Casasola (ed.): Arqueología de la Pesca en el Estrecho de Gibraltar. De la Prehistoria al fin del Mundo Antiguo. Universidad de Cádiz. Cádiz: 8I-I32.

Niveau de Villedary, A.M. (2001a): Las cerámicas gaditanas barnizadas de "tipo Kuass". Tipologia, producción y distribución. Tesis doctoral inédita. Universidad de Cádiz. Cádiz.

Niveua de Villedary, A.M. (2oorb): "Pozos púnicos en la necrópolis de Cádiz: evidencias de prácticas rituales funerarias". Rivista di Studi Fenici, XXIX (2): $183-230$.

Niveau de Villedary, A.M. (2007a): "Salazón y ritual. Una relectura de las factorías de salazones prerromanas de la isla gaditana”. En L. Lagóstena, D. Bernal-Casasola y A. Arévalo (eds.): CETARIAE 2005: Salsas y Salazones de Pescado en Occidente durante la Antigüedad. Actas del Congreso Internacional (Cádiz, 7-9 de noviembre de 2005). British Archaeological Reports International Series, 1686. Archaeopress. Oxford: 4I7-433.
Niveau de Villedary, A.M. (2007b): "Acerca de ciertos cultos semitas extremo-occidentales". Las aguas primigenias: El Próximo Oriente Antiguo como fuente de civilización. Actas del IV Congreso Español de Antiguo Oriente Próximo (Zaragoza, 2006). Instituto de Estudios Islámicos y del Oriente Próximo. Zaragoza: 669-703.

Niveau de Villedary, A.M. (2009): Ofrendas, banquetes y libaciones. El ritual funerario en la necrópolis púnica de Cádiz. Universidad de Sevilla. Sevilla.

Niveau de Villedary, A.M.(20I0): "De comensalidad funeraria: las fosas como testimonio de la celebración de banquetes en la necrópolis. A propósito de dos fosas excavadas en la Ciudad de la Justicia (Cádiz)". En A.M. Niveau de Villedary y V. Gómez Fernández (coords.): Las Necrópolis de Cádiz. Apuntes de arqueologia gaditana en homenaje a FJ. Sibón Olano. Universidad de Cádiz. Cádiz: 179-249.

Niveau de Villedary, A.M. y Abia, A.M. (2014): “El simbolismo del múrex en contextos funerarios y rituales". En J.J. Cantillo, D. Bernal-Casasola y J. Ramos (eds.): Moluscos y púrpura en contextos arqueológicos atlántico-mediterráneos. Nuevos datos y reflexiones en clave de proceso histórico, Actas de la III Reunión Cientifica de Arqueomalacología de la Peninsula Ibérica (3-4 de diciembre de 20I2, Cádiz). Universidad de Cádiz. Cádiz: 287-297.

Niveau de Villedary, A.M.y Ferrer Albelda, E. (2005): "Anotaciones al culto funerario de Gadir: Los pozos rituales". En A. Spanò-Giammellaro (ed.): Atti del $V$ Congresso Internazionale di Studi Fenici e Punici (Marsala-Palermo, 200o), III. Università di Palermo. Palermo: II7I-II86.

O'Connor, S., Mahirta, M., Samper Carro, S.C., Hawkins, S., Kealy, S., Louys, J. y Wood, R. (2017): "Fishing in life and death: Pleistocene fish-hooks from a burial context on Alor Island, Indonesia". Antiquity, 9I (360): I45I-I468.

Perdigones, L. y Muñoz, A. (1987): “Excavaciones de urgencia en un solar de la plaza Asdrúbal (Cádiz) en 1985". Anuario Arqueológico de Andalucía 1985, III. Junta de Andalucía. Sevilla: 58-62.

Perdigones, L. y Muñoz, A. (I99o): "Excavaciones arqueológicas de urgencia en un solar de la calle Tolosa Latour. Extramuros de Cádiz". Anuario Arqueológico de Andalucía 1987, III. Junta de Andalucía. Sevilla: 59-70. 
Purcell N. (1995): "Eating fish: the paradoxes of seafood”. En J. Wilkins, D. Harvey y M. Dobson (eds.): Food in antiquity. University of Exeter. Exeter: 132-I49.

Quintero, P. (I918): Excavaciones a extramuros de la ciudad de Cádiz. Memoria acerca de los resultados obtenidos en I9I7. Madrid.

Robert, L. (1950): Hellenica. Recueil d'épigraphie, de numismatique et d'antiquités grecques IX. Impr.

A. Bontemps. Paris: 80-97.

Rubio Gomis, F. (1986): La necrópolis ibérica de la Albufereta de Alicante (Valencia, España). Valencia.

Sibón,J.F. (200I): Memoria preliminar de los resultados obtenidos de la excavación realizada en la avenida Amilcar Barca. Tesorería General de la Seguridad Social de Cádiz. Junio/Julio 200I. Original inédito depositado en la Delegación Provincial de Cádiz, Consejería de Cultura de la Junta de Andalucía.

Sibón,J.F. (2006a): Memoria final de las excavaciones arqueológicas del Palacio de la Justicia, Cádiz 2004-2005. Tomo I: Sector Sureste. Original inédito depositado en la Delegación Provincial de Cádiz, Consejería de Cultura de la Junta de Andalucía.

Sibón, J.F. (2006b): Memoria final de las excavaciones arqueológicas del Palacio de la Justicia, Cádiz 2004-2005. Tomo III: descripción de la secuencia estratigráfica y conclusiones generales. Original inédito depositado en la Delegación Provincial de Cádiz, Consejería de Cultura de la Junta de Andalucía.

Sibón, J.F. y Córdoba, I. (1998): Informe preliminar arqueológico. Excavación arqueológica de urgencia en el solar de la calle Acacias n ${ }^{\circ} 23$ (Cádiz). Original inédito depositado en la Delegación Provincial de Cádiz, Consejería de Cultura de la Junta de Andalucía.

Sibón J.F., Gómez Fernández, V.y Niveau de Villedary, A.M. (20I0): "Intervención arqueológica de urgencia en el solar de la futura Ciudad de la Justicia (Cádiz)". Anuario Arqueológico de Andalucia 2004. Junta de Andalucía. Sevilla: I48-158.
Vaquerizo, D. (2010): "Espacios y usos funerarios en el Gades romano. ¿Un lujo sacrificable...?”. En A.M. Niveau de Villedary y V. Gómez Fernández (coords.): Las Necrópolis de Cádiz. Apuntes de arqueología gaditana en homenaje a FJ. Sibón Olano. Universidad de Cádiz. Cádiz: 34I-385.

Vargas, J.M. (2017): El instrumental de pesca en Hispania. Origen, desarrollo y contextualización atlántico-mediterránea. Tesis doctoral inédita. Universidad de Cádiz. Cádiz.

Vargas, J.M. (ed.) (2020): El instrumental de pesca en el Fretum Gaditanum: catalogación, análisis tipo-cronológico y comparativa regional. Archaeopress. Oxford.

\section{Fuentes clásicas}

\section{Alcifrón: Cartas}

Edición en castellano. Teofrasto: Caracteres. Alcifrón: Cartas de pescadores, campesinos, parásitos y cortesanas. Introducciones, traducciones y notas por Elisa Ruíz García. Editorial Gredos. Madrid, I988.

\section{Opiano: Haliéutica}

Edición en castellano. Opiano: De la Caza, De la Pesca, Lapidario Órfico (Anónimo). Traducciones, introducciones y notas de Carmen Calvo Delcán. Editorial Gredos. Madrid, I990.

\section{Plauto: Captivi}

Edición en castellano. Plauto: Captivi. Los prisioneros. Versión de Juan Luis Arcaz Pozo y Antonio López Fonseca. Ediciones Clásicas. Madrid, 1998.

\section{Plauto: Rudens}

Edición en castellano. Plauto: Comedias: Auluaria, Anfitrión, Rudens. Edición de Eudaldo Solá Farrés. Libro Clásico (Bruguera). Barcelona, r98r.

Teócrito: Idilios

Edición en castellano. Bucólicos griegos. Introducciones, traducciones y notas por Manuel García Teijeiro y M. Teresa Molinos Tejada. Editorial Gredos. Madrid, 1986. 